\title{
Influences of Pore-Water Pressure on Slope Stability considering Strength Nonlinearity
}

\author{
Di Wu ${ }^{(D)},{ }^{1}$ Yuke Wang $\left(\mathbb{D},{ }^{2}\right.$ Fei Zhang $\left(\mathbb{D},{ }^{3}\right.$ and Yue Qiu $\mathbb{D}^{4}$ \\ ${ }^{1}$ College of Architectural Engineering, Qingdao Binhai University, Qingdao 266555, China \\ ${ }^{2}$ College of Water Conservancy Science and Engineering, Zhengzhou University, Zhengzhou 450001, China \\ ${ }^{3}$ Key Laboratory of Ministry of Education for Geomechanics and Embankment Engineering, Hohai University, \\ Nanjing 210098, China \\ ${ }^{4}$ State Key Laboratory of Mining Disaster Prevention and Control Co-founded by Shandong Province and \\ the Ministry of Science and Technology, Shandong University of Science and Technology, Qingdao 266590, China
}

Correspondence should be addressed to Yuke Wang; wangyuke@zzu.edu.cn

Received 5 June 2020; Accepted 11 May 2021; Published 26 May 2021

Academic Editor: Xinyu Ye

Copyright (C) 2021 Di Wu et al. This is an open access article distributed under the Creative Commons Attribution License, which permits unrestricted use, distribution, and reproduction in any medium, provided the original work is properly cited.

The pore-water pressure is a vital factor in determining the slope stability. To deal with the stability of slopes undergoing porewater pressures, this paper used the pore-water pressure coefficient to develop the three-dimensional limit analysis method for slope stability evaluation with a nonlinear strength envelope. For numerical slope examples, the critical heights and corresponding critical slip surfaces associated with linear and nonlinear envelopes were derived by using a numerical optimization procedure. The influences of pore-water pressures on the slope stability were addressed by comparing the upper-bound solutions derived by linear and nonlinear strength envelopes (the linear and nonlinear results for short). The obtained two critical inclinations between the linear and nonlinear results both decrease and gradually approach with increasing pore-water pressure coefficient. For most slopes subjected to pore-water pressures, using the linear Mohr-Coulomb envelope will obviously overestimate the slope critical height. The overestimation resulted from the linear criterion will become more distinct for slopes with smaller widths. Besides, the presented results showed that the equivalent internal friction angle tends to have a weaker increasing trend for steeper slopes as pore-water pressure coefficient increases. Hence, when pore-water pressure coefficient increases, the critical slip surfaces of gentle slopes with nonlinear strength criteria become shallower, but the critical slip surfaces of steep slopes seem to have no consistent change law. These results and analyses can illustrate the significance of the application of nonlinear strength envelopes in slope stability evaluation considering pore-water pressures and provide certain reference advice in slope engineering design and landslide prevention.

\section{Introduction}

In the common analysis methods and design standards for slope and foundation stability problems, the soil shear strength is generally represented in the type of the linear Mohr-Coulomb (MC) strength envelope (e.g., Chen [1], Michalowski and Drescher [2], Gao et al. [3], Rao et al. [4], Yang et al. [5], and Ye et al. [6,7]). Whereas, a number of experimental studies [8-13] have revealed that the shear strength envelopes for almost all geomaterials are nonlinear, particularly in low normal stress range, which is commonly relevant to the stress distribution on sliding surfaces of instable slopes. Afterwards, numerous studies performed the slope stability assessment with nonlinear strength envelopes by using the conventional limit equilibrium method (e.g., Charles and Soares [14], Srbulov [15], Jiang et al. [16], Baker [17, 18], Eid [19, 20], and Deng and Li [21]), the limit analysis method (e.g., Drescher and Christopoulos [22], Yang and Yin [23], Gao et al. [24], Zhao et al. [25], and Li and Yang [26]), and the numerical method (e.g., Popescu et al. [27], Li [28], Li and Cheng [29], and $\mathrm{Li}$ and Yang [30]).

With the increasing concern about the effects of shear strength nonlinearity on slope stability evaluation, many 
studies have drawn further distinctions between the slope safety with linear and nonlinear strength criteria $[14-18,20,24,27,30]$. Some results revealed that the use of linear envelope will overestimate critical heights of most slopes with nonlinear envelopes, but will underestimate the stability of slopes in a middle range of inclinations $[18,24]$. The overestimation or underestimation resulted from the use of the linear failure criterion is more significant for slopes in three-dimensional (3D) conditions $[16,24]$. Besides, the effects of nonlinear strength parameters on slope slip surfaces were addressed by Charles and Soares [14] and Zhao et al. [25]. Jiang et al. [16] and Baker [17] further illustrated the significant distinctions between slip surfaces of several two-dimensional (2D) slope examples with linear and nonlinear envelopes. These evidences highlight that the application of nonlinear strength envelopes is significant in slope stability evaluation.

As known, the presence of ground water can lead to the reduction in slope stability with the linear MC strength criterion (e.g., Michalowski and Nadukuru [31], Gao et al. [32], Pan et al. [33], and Zhu et al. [34]). To evaluate the influence of ground water on slope stability assessment by using nonlinear failure criteria, Yang and Zou [35] considered pore-water pressures as external forces to present limit analysis of rock slope stability with the Hoek-Brown envelope. Saada et al. [36] then used the obtained pore-water pressure distributions to develop the limit analysis method for slope stability evaluation with the Hoek-Brown envelope. Besides, Eid [20] adopted the limit equilibrium method to analyze the safety of $2 \mathrm{D}$ saturated slopes with a simple nonlinear criterion. For slopes in $3 \mathrm{D}$ conditions, $\mathrm{Xu}$ et al. [37] considered different water drawdown conditions in the limit analysis method for slope safety evaluation with Hoek-Brown envelope. Previous studies failed to address the effects of pore-water pressures on the distinctions between the slope stability solutions associated with linear and nonlinear strength envelopes (the linear and nonlinear results for short), especially for soil slopes considering 3D characteristic.

The aim of this paper was to further explore the influences of pore-water pressures on 3D slope stability evaluation associated with linear and nonlinear criteria. For soil slopes subjected to pore-water pressures, the 3D limit analysis method with a nonlinear strength envelope was firstly established through the uses of tangential technique and pore-water pressure coefficient. Then, the slope critical heights and corresponding slip surfaces were derived for several slope examples with linear and nonlinear strength envelopes. Afterwards, the comparative charts were presented to reveal the differences between linear and nonlinear solutions considering different pore-water pressures and slope geometries.

\section{3D Limit Analysis Method for Slope Stability}

2.1. Tangential Technique for Nonlinear Strength Criterion. To represent the nonlinear feature of strength envelopes of slope soils, a power-law (PL) strength criterion (Figure 1) was commonly used by many researchers to evaluate the safety of slopes [23-25, 38]. As shown in equation (1), the shear stress $\tau$ along slope slip surface is derived from an expression of normal stress $\sigma_{\mathrm{n}}$ :

$$
\tau=c_{0}\left(1+\frac{\sigma_{n}}{\sigma_{t}}\right)^{1 / m}
$$

where $c_{0}$ relates to the initial cohesion as $\sigma_{\mathrm{n}}$ is $0, \sigma_{\mathrm{t}}$ relates to the tensile stress as $\tau$ is 0 , and $m$ is named as the nonlinearity coefficient. The PL criterion can transform into the MC criterion when $m=1$. Under such a condition, the cohesion is represented by $c_{0}$ and the friction angle is represented by $\arctan \left(c_{0} / \sigma_{\mathrm{t}}\right)$.

Since the nonlinear strength criterion cannot be directly used in the assessment of slope stability, Drescher and Christopoulos [22] firstly presented a tangential technique in limit analysis of soil slope stability. Afterwards, numerous researchers developed the tangential technique to assess the slope safety considering shear strength nonlinearity $[23-25,30,39]$. These studies may reveal that the upperbound solutions obtained from the tangential technique are accurate and reliable to bracket the true stability of $2 \mathrm{D}$ and $3 \mathrm{D}$ slopes with a nonlinear criterion. From Figure 1, it can be observed that the PL strength envelope is substituted by the tangent line at point $\mathrm{K}$, which is expressed in the following equation:

$$
\tau=c_{e}+\sigma_{n} \tan \phi_{e}
$$

where $\phi_{e}$ is defined as the equivalent friction angle and $c_{\mathrm{e}}$ is the equivalent cohesion. It should be noted that the tangent line will lead to equivalent or higher shear strengths in the same range of normal stresses for PL strength envelope. After certain formula manipulations for PL strength criterion, the expression of equivalent cohesion $c_{\mathrm{e}}$ will be derived as follows:

$$
\frac{c_{e}}{c_{0}}=\frac{m-1}{m}\left[\frac{\sigma_{t}}{c_{0}} m \tan \phi_{e}\right]^{(1 /(1-m))}+\frac{\sigma_{t}}{c_{0}} \tan \phi_{e} .
$$

As shown in equation (3), the equivalent cohesion $c_{\mathrm{e}}$ is an equation with respect to equivalent friction angle $\phi_{e}$.

2.2. 3D Failure Mechanisms. In the upper-bound limit analysis for soil slope stability using linear MC envelope, Gao et al. [3] modified the 3D failure mechanisms of Michalowski and Drescher [2] by considering the slip surfaces above or below slope toe. Afterwards, Gao et al. [24] combined nonlinear PL envelope into these extended 3D failure mechanisms to conduct the limit analysis of slope stability. Similarly, this study used these 3D failure mechanisms with nonlinear PL envelope to assess slope stability considering pore-water pressures.

Figures 2 and 3 describe these extended 3D rotational mechanisms for slopes obeying PL failure envelope. These 3D failure mechanisms are composed of a curvilinear cone and a plane insertosome. The width of plane insertosome is marked by $b$, slope width is expressed by $B$, and slope height is expressed by $H$. The apex angle of failure mechanism is represented by the variable $\phi_{e}$, which is the equivalent friction angle derived from the PL envelope. These $3 \mathrm{D}$ 


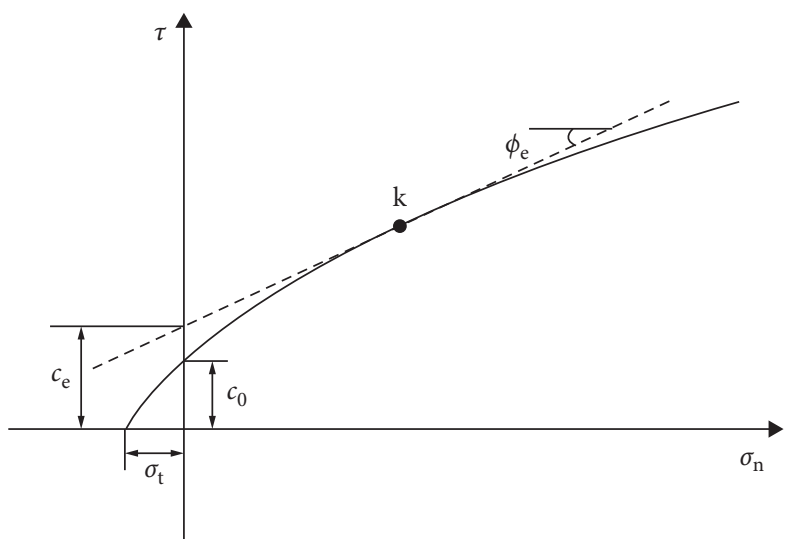

- Power-law criterion

- - - Tangential line

FIgURE 1: Tangent line to nonlinear strength envelope.

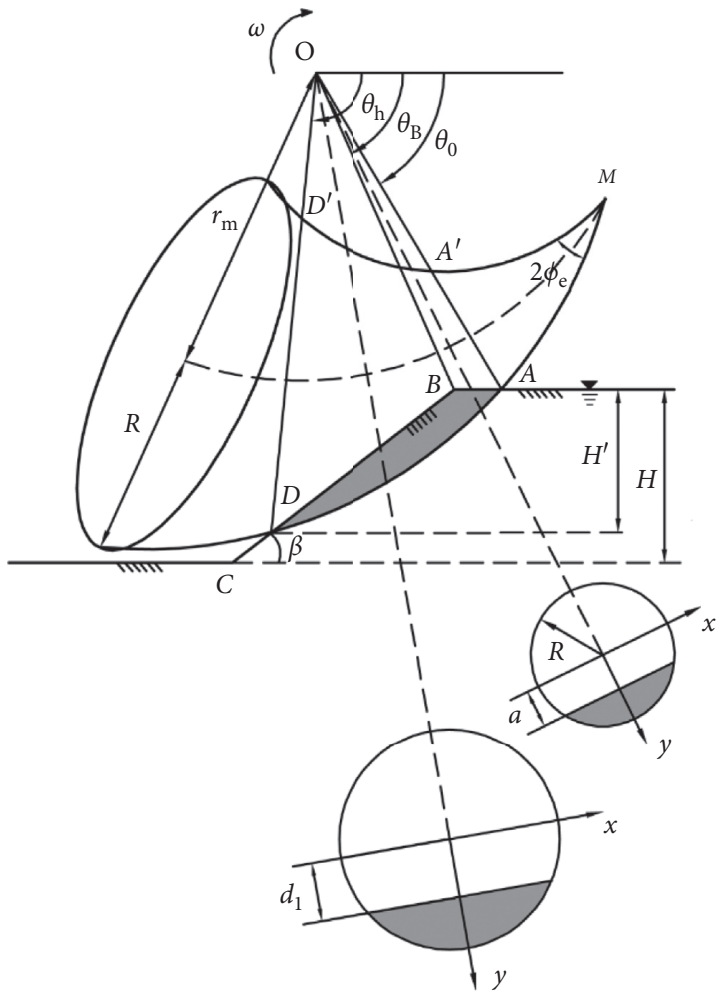

(a)

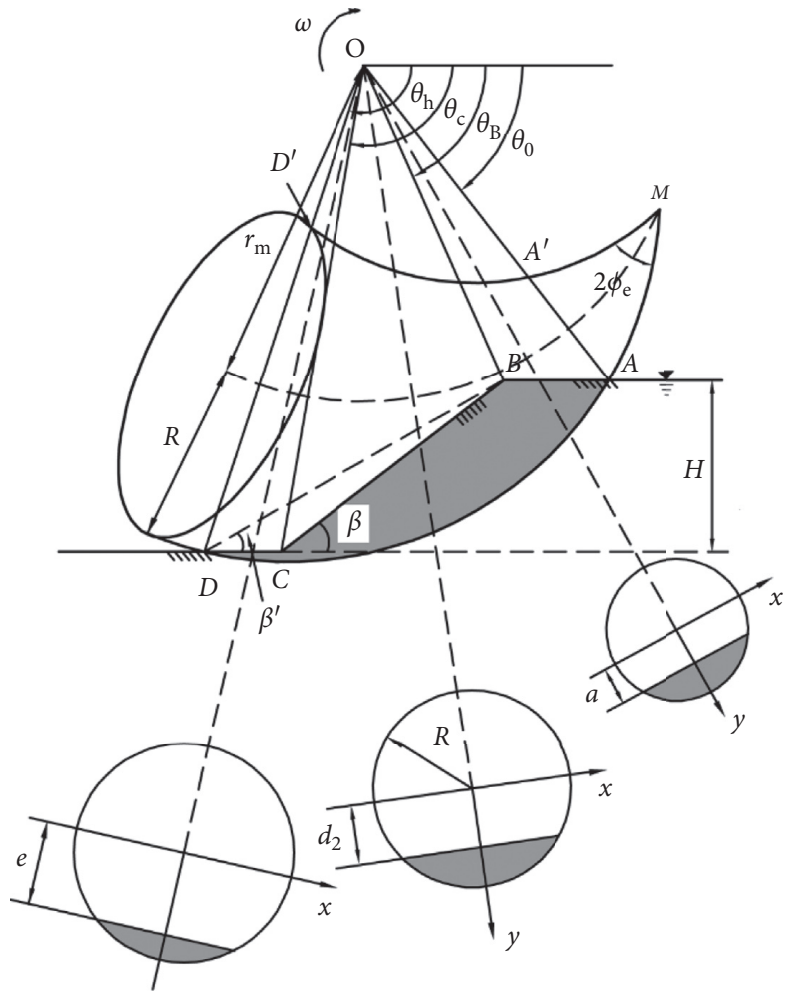

(b)

FIGURE 2: Side view of modified 3D failure mechanisms [3]. (a) Face-failure mechanism. (b) Base-failure mechanism.

failure mechanisms will be translated into the planestrain mechanisms when the width of plane insertosome tends to infinitely great. See the source reference of Gao et al. [3], for more interpretations for 3D failure mechanisms.

2.3. Work Rate Done by Pore-Water Pressure. For the above $3 \mathrm{D}$ rotational mechanisms, the external forces on the sliding body contain the pore-water pressure and the soil weight. Pore-water pressure $u$ is commonly described as some portion of soil self-weight (e.g., Michalowski and Nadukuru
[31], Gao et al. [32], and Xu et al. [37]), which is presented as the following equation:

$$
u=r_{u} \gamma h,
$$

where $r_{\mathrm{u}}$ is defined as pore-water pressure coefficient and $\gamma$ represents soil unit weight. The parameter $h$ relates to the vertical distance between the position of pore-water pressure and the slope surface.

Making the work rates done from the soil weight $W_{\gamma}$ and the pore-water pressure $W_{u}$ equal to the internal energy 


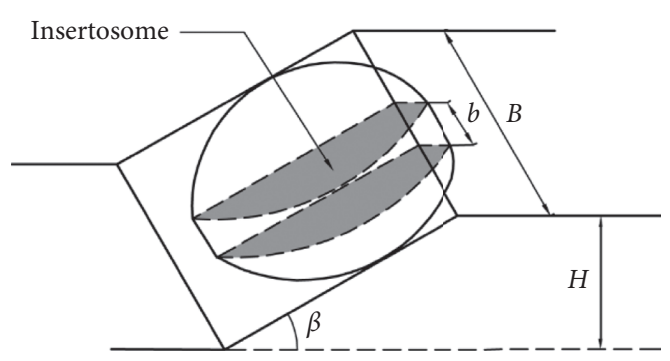

(a)

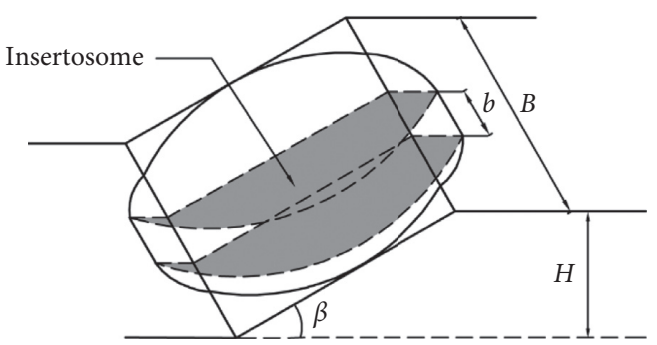

(b)

FIGURE 3: Oblique view of modified 3D failure mechanisms [3]. (a) Face-failure mechanism. (b) Base-failure mechanism.

dissipation rates $D$, the establishment of the energy-balance equation for above $3 \mathrm{D}$ rotational mechanisms can be presented as follows:

$$
W_{\gamma}^{\text {curve }}+W_{\gamma}^{\text {plane }}+W_{u}^{\text {curve }}+W_{u}^{\text {plane }}=D^{\text {curve }}+D^{\text {plane }},
$$

where $W_{\gamma}^{\text {curve }}$ and $W_{\gamma}^{\text {plane }}$ relate to the work rates done by soil weight for curvilinear cone and plane insertosome, $W_{\gamma}^{\text {curve }}$ and $W_{\gamma}^{\text {plane }}$ represent work rates done by pore-water pressure for curvilinear cone and plane insertosome, and $D^{\text {curve }}$ and $D^{\text {plane }}$ represent internal energy dissipation rates for curvilinear cone and plane insertosome. Detailed equations and illustrations for soil weight work rates and internal energy dissipation rates for curvilinear cone and plane insertosome have been illustrated in certain references of Gao et al. [3] and Chen [1]. Note that the friction angle $\phi$ in these formulas needs to be replaced by the equivalent friction angle $\phi_{e}$. Work rates for pore-water pressure $W_{u}$ can be derived from the following formula $[31,32]$ :

$$
W_{u}=-\int_{V} u \dot{\varepsilon}_{i i} \mathrm{~d} V-\int_{s} u n_{i} v_{i} \mathrm{~d} S,
$$

in which $h / r_{0}$ relates to the principal strain rate, $V$ relates to the volume of the sliding body under the water, $n_{i}$ relates to the outer unit normal vector of slope boundary, $v_{i}$ represents unit velocity vector on slope boundary, and $S$ is the sliding surface under the water.

Here, the whole potential sliding body will be regarded as a rigid body without considering the water pressure on the slope surface. Hence, the expression for work rates of porewater pressure $W_{u}$ turns into the following equation:

$$
W_{u}=-\int_{s} u n_{i} v_{i} \mathrm{~d} S=-\int_{s} r_{u} \gamma h v \sin \phi_{e} \mathrm{~d} S .
$$

Considering the fact that the pore-water pressure on curvilinear cone boundary (along the width) varies according to the degree of the surface curvature, this study adopted the calculation method given by Gao et al. [32] to obtain the work rates of pore-water pressure for presented 3D slip surfaces.

For 3D face-failure mechanism with the nonlinear criterion (Figures 2(a) and 3(a)), the pore-water pressure work rates for curvilinear cone $W_{u}^{\text {curve }}$ are obtained from this equation:

$$
W_{u}^{\text {curve }}=2 \omega \gamma r_{u} \tan \phi_{e}\left[\int_{\theta_{0}}^{\theta_{B}} \int_{a}^{R} h_{1} \eta \mathrm{d} y \mathrm{~d} \theta+\int_{\theta_{B}}^{\theta_{P}} \int_{d_{1}}^{g} h_{2} \eta \mathrm{d} y \mathrm{~d} \theta+\int_{\theta_{B}}^{\theta_{P}} \int_{g}^{R} h_{1} \eta \mathrm{d} y \mathrm{~d} \theta+\int_{\theta_{P}}^{\theta_{h}} \int_{d_{1}}^{R} h_{2} \eta \mathrm{d} y \mathrm{~d} \theta\right],
$$

and the pore-water pressure work rates for plane insertosome $W_{u}^{\text {plane }}$ are expressed as

$$
W_{u}^{\mathrm{plane}}=\omega \gamma r_{u} r_{0}^{2} b \tan \phi_{e}\left[\int_{\theta_{0}}^{\theta_{P}} h_{1} \exp ^{2 \tan \phi_{e}\left(\theta-\theta_{0}\right)} \mathrm{d} \theta+\int_{\theta_{P}}^{\theta_{h}} h_{2} \exp ^{2 \tan \phi_{e}\left(\theta-\theta_{0}\right)} \mathrm{d} \theta\right]
$$


where the relations between these parameters can be given as follows:

$$
\begin{aligned}
a & =\frac{\sin \theta_{0}}{\sin \theta} r_{0}-r_{m}, \\
d_{1} & =\frac{\sin \left(\theta_{h}+\beta\right)}{\sin (\theta+\beta)} e^{\left(\theta_{h}-\theta_{0}\right) \tan \phi_{e}} r_{0}-r_{m}, \\
g & =\frac{r_{0} \cos \theta_{0}-L}{\cos \theta}-r_{m}, \\
\eta & =\left(r_{m}+y\right)^{2} \frac{R}{\sqrt{R^{2}-y^{2}}}, \\
\theta_{B} & =\arctan \frac{\sin \theta_{0}}{\cos \theta_{0}-A^{\prime}}, \\
A^{\prime} & =\frac{\sin \left(\theta_{h}-\theta_{0}\right)}{\sin \theta_{h}}-\frac{\sin \left(\theta_{h}+\beta\right)}{\sin \theta_{h} \sin \beta}\left(\sin \theta_{h} e^{\left(\theta_{h}-\theta_{0}\right) \tan \phi_{e}}-\sin \theta_{0}\right),
\end{aligned}
$$

$$
\begin{aligned}
& \cos \theta_{P} e^{\left(\theta_{P}-\theta_{0}\right) \tan \phi_{e}}=\cos \theta_{0}-\frac{L}{r_{0}}, \\
& \frac{L}{r_{0}}=\frac{\sin \left(\theta_{h}-\theta_{0}\right)}{\sin \theta_{h}}-\frac{\sin \left(\theta_{h}+\beta\right)}{\sin \theta_{h} \sin \beta}\left[\exp ^{\tan \phi_{e}\left(\theta_{h}-\theta_{0}\right)} \sin \theta_{h}-\sin \theta_{0}\right], \\
& \frac{h_{1}}{r_{0}}=\exp ^{\tan \phi_{e}\left(\theta-\theta_{0}\right)} \sin \theta-\sin \theta_{0},
\end{aligned}
$$

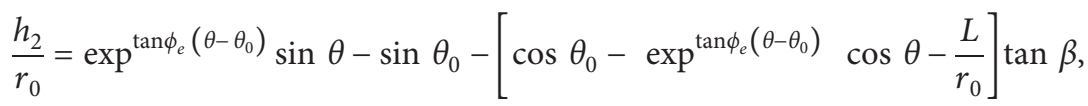

where $\omega$ is the angular velocity and $r_{0}$ and $r_{0}{ }^{\prime}$ relate to OA and $\mathrm{OA}^{\prime}$ in Figure 2 . The parameters $\theta_{0}, \theta_{B}, \theta_{h}, R$, and $r_{m}$ are presented in Figure 2(a), and the definitions of the parameters $h_{1}, h_{2}$, and $\theta_{p}$ can be found in Figure 4.
As shown in Figures 2(b) and 3(b), the pore-water pressure work rates for curvilinear cone and plane insertosome of 3D base-failure mechanism can be derived from the following expressions:

$$
\begin{aligned}
& W_{u}^{\text {curve }}=2 \omega \gamma r_{u} \tan \phi_{e}\left[\int_{\theta_{0}}^{\theta_{B}} \int_{a}^{R} h_{1} \eta \mathrm{d} y \mathrm{~d} \theta+\int_{\theta_{B}}^{\theta_{P}} \int_{d_{2}}^{g} h_{2} \eta \mathrm{d} y \mathrm{~d} \theta+\int_{\theta_{B}}^{\theta_{P}} \int_{g}^{R} h_{1} \eta \mathrm{d} y \mathrm{~d} \theta\right. \\
& \left.+\int_{\theta_{P}}^{\theta_{G}} \int_{d_{2}}^{R} h_{2} \eta \mathrm{d} y \mathrm{~d} \theta+\int_{\theta_{G}}^{\theta_{C}} \int_{d_{2}}^{f} h_{2} \eta \mathrm{d} y \mathrm{~d} \theta+\int_{\theta_{G}}^{\theta_{C}} \int_{f}^{R} h_{3} \eta \mathrm{d} y \mathrm{~d} \theta+\int_{\theta_{C}}^{\theta_{h}} \int_{e}^{R} h_{3} \eta \mathrm{d} y \mathrm{~d} \theta\right], \\
& W_{u}^{\text {plane }}=\omega \gamma r_{u} r_{0}^{2} b \tan \phi_{e}\left[\int_{\theta_{0}}^{\theta_{P}} h_{1} \exp ^{2 \tan \phi_{e}\left(\theta-\theta_{0}\right)} \mathrm{d} \theta\right. \\
& \left.+\int_{\theta_{P}}^{\theta_{G}} h_{2} \exp ^{2 \tan \phi_{e}\left(\theta-\theta_{0}\right)} \mathrm{d} \theta+\int_{\theta_{G}}^{\theta_{h}} h_{3} \exp ^{2 \tan \phi_{e}\left(\theta-\theta_{0}\right)} \mathrm{d} \theta\right],
\end{aligned}
$$

where some relations between these parameters can be obtained as follows: 


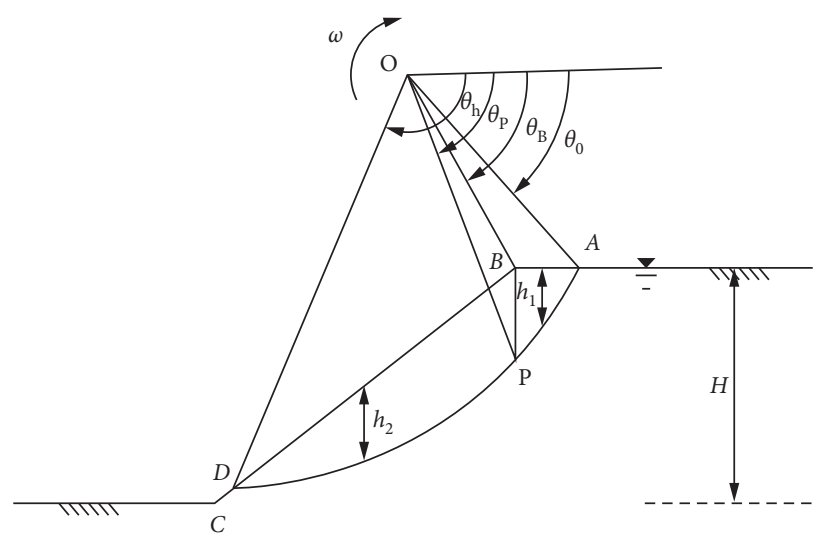

Figure 4: Symmetry plane of face-failure mechanism with ground water.

$$
\begin{aligned}
& d_{2}=\frac{\sin \left(\theta_{C}+\beta\right) \sin \theta_{h}}{\sin (\theta+\beta) \sin \theta_{C}} e^{\left(\theta_{h}-\theta_{0}\right) \tan \phi_{e}} r_{0}-r_{m} \\
& e=\frac{\sin \theta_{h}}{\sin \theta} e^{\left(\theta_{h}-\theta_{0}\right) \tan \phi_{e}} r_{0}-r_{m} \\
& \theta_{C}=\arctan \frac{\sin \theta_{h} e^{\left(\theta_{h}-\theta_{0}\right) \tan \phi_{e}}}{\cos \theta_{0}-A^{\prime}-\left(\sin \theta_{h} e^{\left(\theta_{h}-\theta_{0}\right) \tan \phi_{e}}-\sin \theta_{0}\right) / \tan \beta}, \\
& f=\frac{r_{0} \cos \theta_{0}-L-H \cot \beta}{\cos \theta}-r_{m}, \\
& \cos \theta_{G} e^{\left(\theta_{G}-\theta_{0}\right) \tan \phi_{e}}=\cos \theta_{0}-\frac{H}{r_{0}} \cot \beta-\frac{L}{r_{0}}, \\
& \frac{h_{3}}{r_{0}}=\exp ^{\tan \phi_{e}\left(\theta-\theta_{0}\right)} \sin \theta-\sin \theta_{0}-\frac{H}{r_{0}}, \\
& \frac{H}{r_{0}}=\exp \left[\tan \phi_{e}\left(\theta_{h}-\theta_{0}\right)\right] \sin \theta_{h}-\sin \theta_{0}
\end{aligned}
$$

where $h_{3}$ and $\theta_{G}$ are defined as shown in Figure 5 , and the other parameters are defined in Figures 2(b) and 5.

\subsection{Determination of Critical Heights and Critical Slip} Surfaces. Given a slope with certain nonlinear parameters, geometric parameters, and pore-water pressure, the upper bound on critical height $H_{\mathrm{cr}}$ (when the slope safety factor is equal to 1.0) could be calculated from above-established energy-balance equation in regard to several independent variables: $\theta_{0}, \theta_{h}, r_{0}{ }^{\prime} / r_{0}, b / H, n=H^{\prime} / H$ (3D face-failure mechanism) or $\beta^{\prime}$ (3D base-failure mechanism), and equivalent friction angle $\phi_{e}$. The critical height $H_{\mathrm{cr}}$ can be expressed as the following formula:

$$
H_{c r}=\left\{\begin{array}{l}
f\left(\theta_{0}, \theta_{h}, \phi_{e}, r_{0}^{\prime} / r_{0}, b / B, n\right) \quad \text { 3D face }- \text { failure mechanism, } \\
f\left(\theta_{0}, \theta_{h}, \phi_{e}, r_{0}^{\prime} / r_{0}, b / B, \beta^{\prime}\right) \quad \text { 3D base - failure mechanism. }
\end{array}\right.
$$




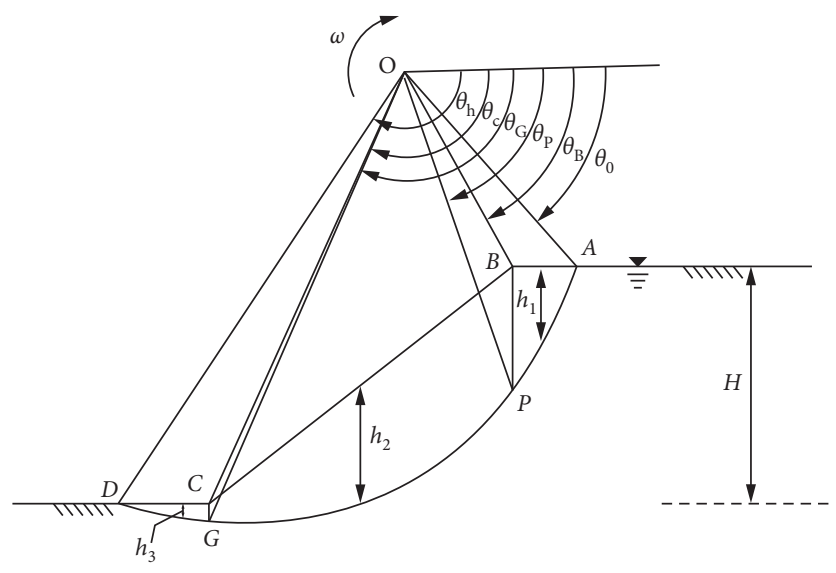

FIGURE 5: Symmetry plane of base-failure mechanism with ground water.
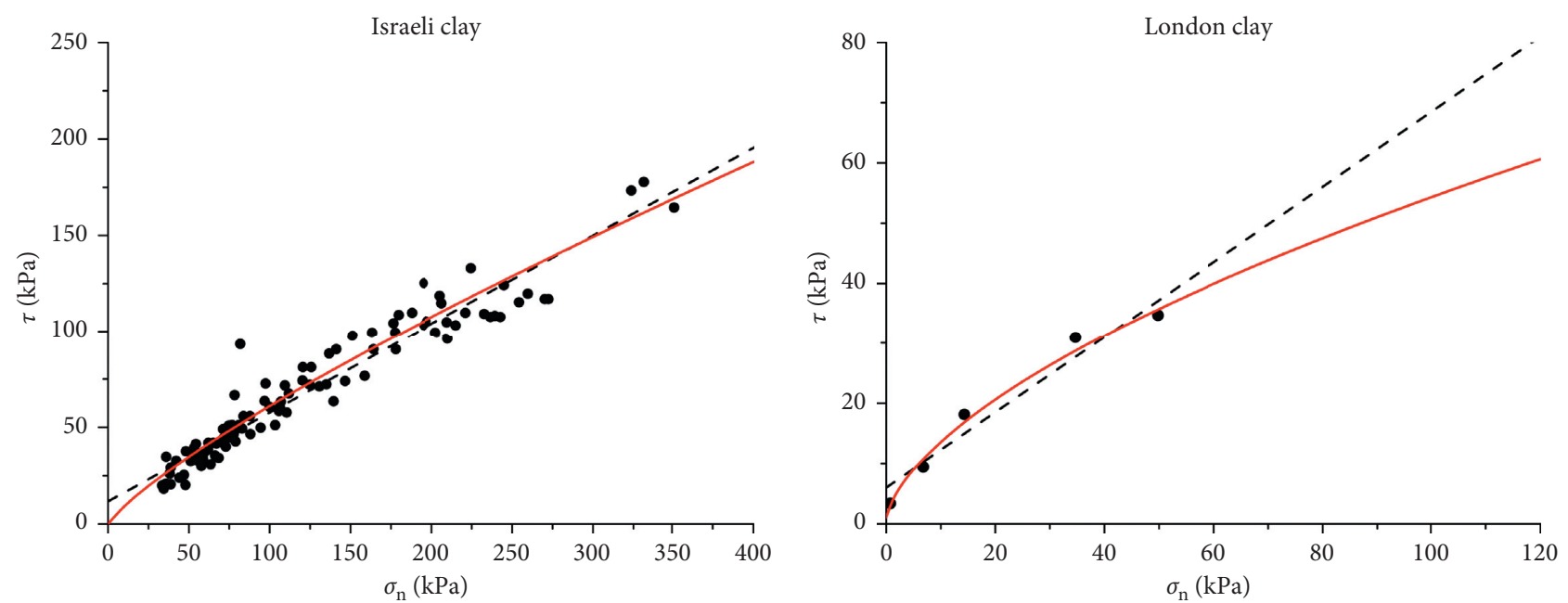

_ Nonlinear failure criterion

_. - Linear failure criterion

_ Nonlinear failure criterion

- - - Linear failure criterion

(a)

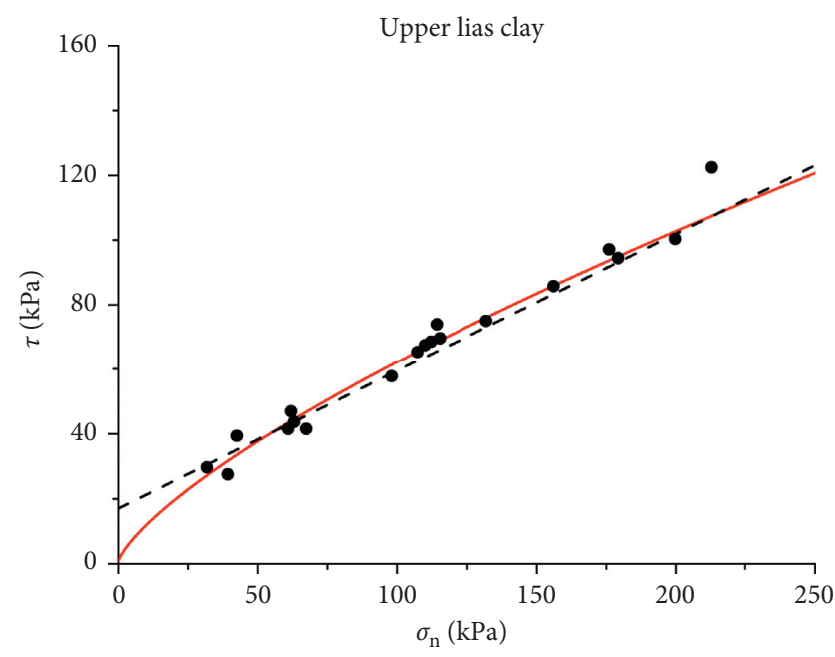

(b)

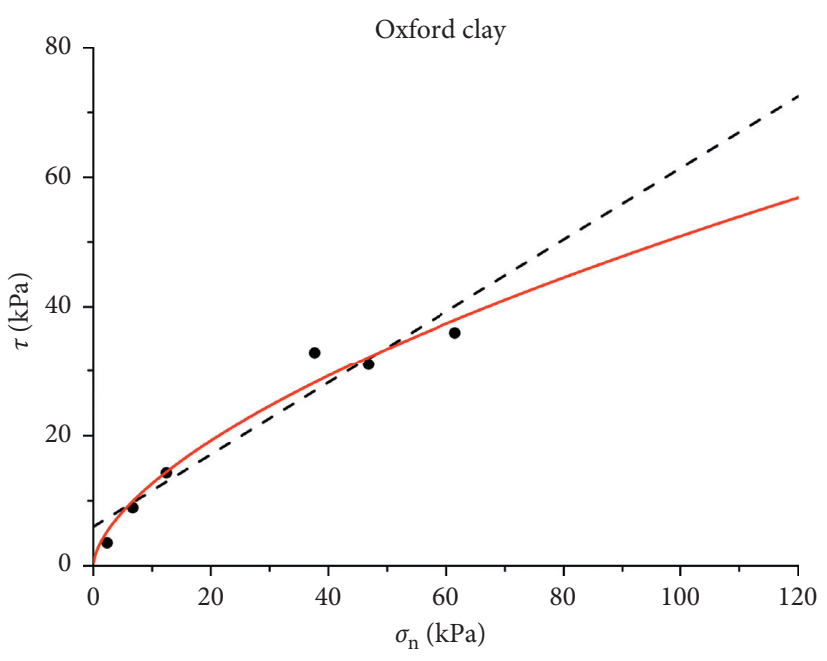

- Nonlinear failure criterion

- - - Linear failure criterion

_ Nonlinear failure criterion

- - - Linear failure criterion

(c)

(d)

Figure 6: Experiment data and two failure criteria for four clays. (a) Israeli clay. (b) London clay. (c) Upper Lias clay. (d) Oxford clay. 
TABLE 1: Unit weight and strength parameters for four clays.

\begin{tabular}{lcccc}
\hline Soil parameters & Israeli clay & London clay & $\begin{array}{c}\text { Upper Lias } \\
\text { clay }\end{array}$ & $\begin{array}{c}\text { Oxford } \\
\text { clay }\end{array}$ \\
\hline$\gamma\left(\mathrm{kN} / \mathrm{m}^{3}\right)$ & 18.0 & 18.0 & 20.0 & 20.0 \\
$c(\mathrm{kPa})$ & 11.7 & 6.0 & 17.0 & 6.0 \\
$\phi\left({ }^{\circ}\right)$ & 24.7 & 32.0 & 23.0 & 29.0 \\
$c_{0}(\mathrm{kPa})$ & 0.06 & 1.07 & 0.98 & 0.16 \\
$\sigma_{\mathrm{t}}(\mathrm{kPa})$ & 0.02 & 0.15 & 0.33 & 0.007 \\
$m$ & 1.23 & 1.66 & 1.38 & 1.65 \\
\hline
\end{tabular}

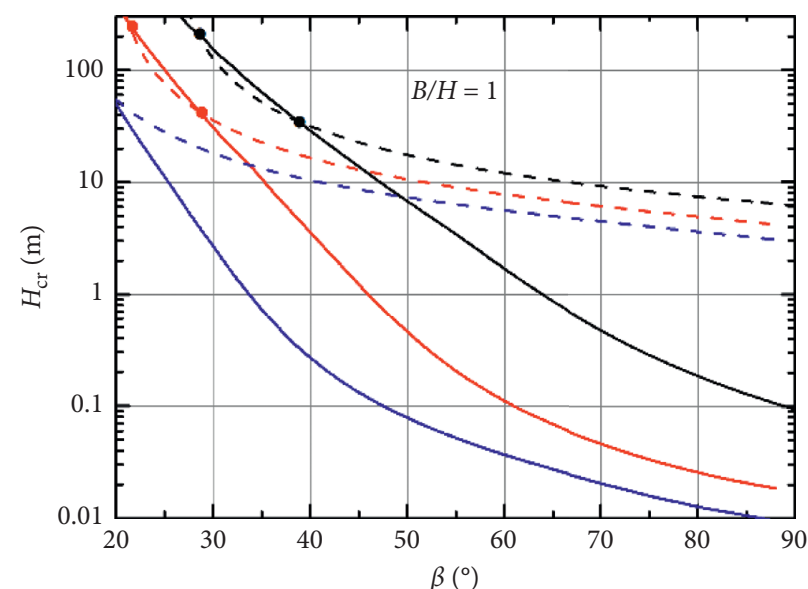

- Nonlinear results $\left(r_{\mathrm{u}}=0\right)$

- - - Linear results $\left(r_{\mathrm{u}}=0\right)$

— Nonlinear results $\left(r_{\mathrm{u}}=0.25\right)$

- - - Linear results $\left(r_{\mathrm{u}}=0.25\right)$

- Nonlinear results $\left(r_{\mathrm{u}}=0.5\right)$

- - Linear results $\left(r_{\mathrm{u}}=0.5\right)$

(a)

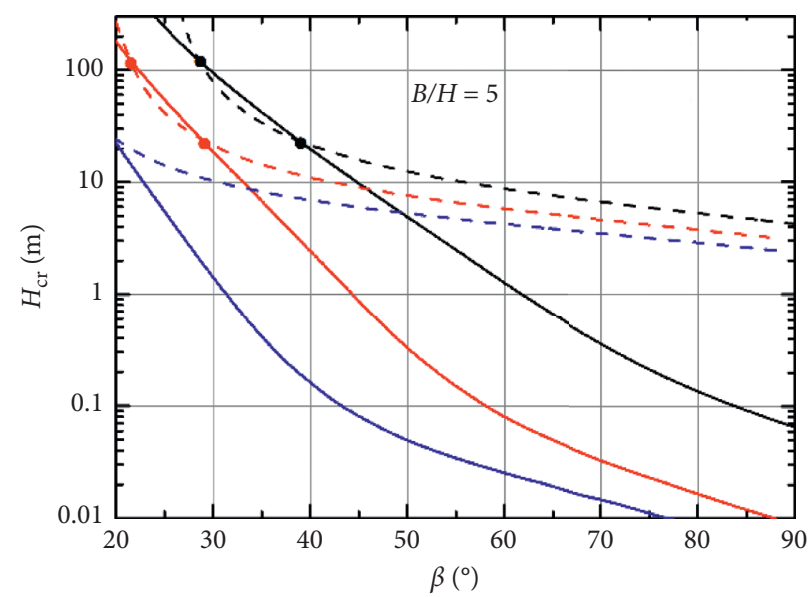

- Nonlinear results $\left(r_{\mathrm{u}}=0\right)$

- - - Linear results $\left(r_{\mathrm{u}}=0\right)$

- Nonlinear results $\left(r_{\mathrm{u}}=0.25\right)$

- - - Linear results $\left(r_{\mathrm{u}}=0.25\right)$

- Nonlinear results $\left(r_{\mathrm{u}}=0.5\right)$

- - - Linear results $\left(r_{\mathrm{u}}=0.5\right)$

(c)

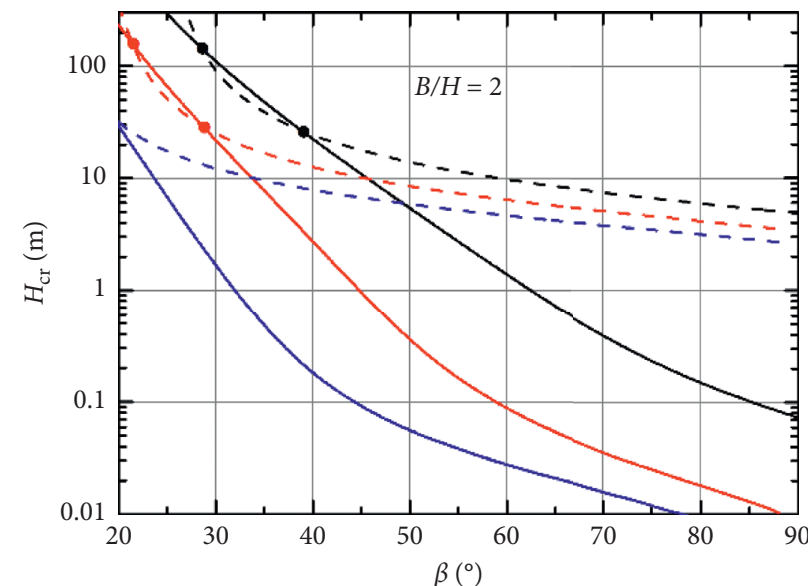

- Nonlinear results $\left(r_{\mathrm{u}}=0\right)$

- - - Linear results $\left(r_{\mathrm{u}}=0\right)$

- Nonlinear results $\left(r_{\mathrm{u}}=0.25\right)$

- - - Linear results $\left(r_{\mathrm{u}}=0.25\right)$

- Nonlinear results $\left(r_{\mathrm{u}}=0.5\right)$

- - - Linear results $\left(r_{\mathrm{u}}=0.5\right)$

(b)

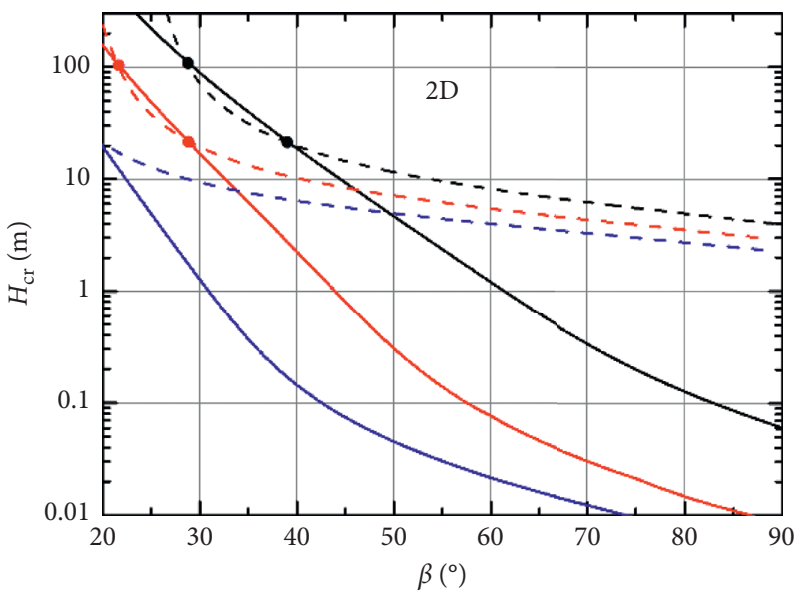

- Nonlinear results $\left(r_{\mathrm{u}}=0\right)$

- - - Linear results $\left(r_{\mathrm{u}}=0\right)$

- Nonlinear results $\left(r_{\mathrm{u}}=0.25\right)$

- - - Linear results $\left(r_{\mathrm{u}}=0.25\right)$

- Nonlinear results $\left(r_{\mathrm{u}}=0.5\right)$

- - - Linear results $\left(r_{\mathrm{u}}=0.5\right)$

(d)

Figure 7: Critical heights of Israeli clay slopes undergoing different pore-water pressures. (a) $B / H=1$. (b) $B / H=2$. $(c) B / H=5$. $(d) 2 D$. 

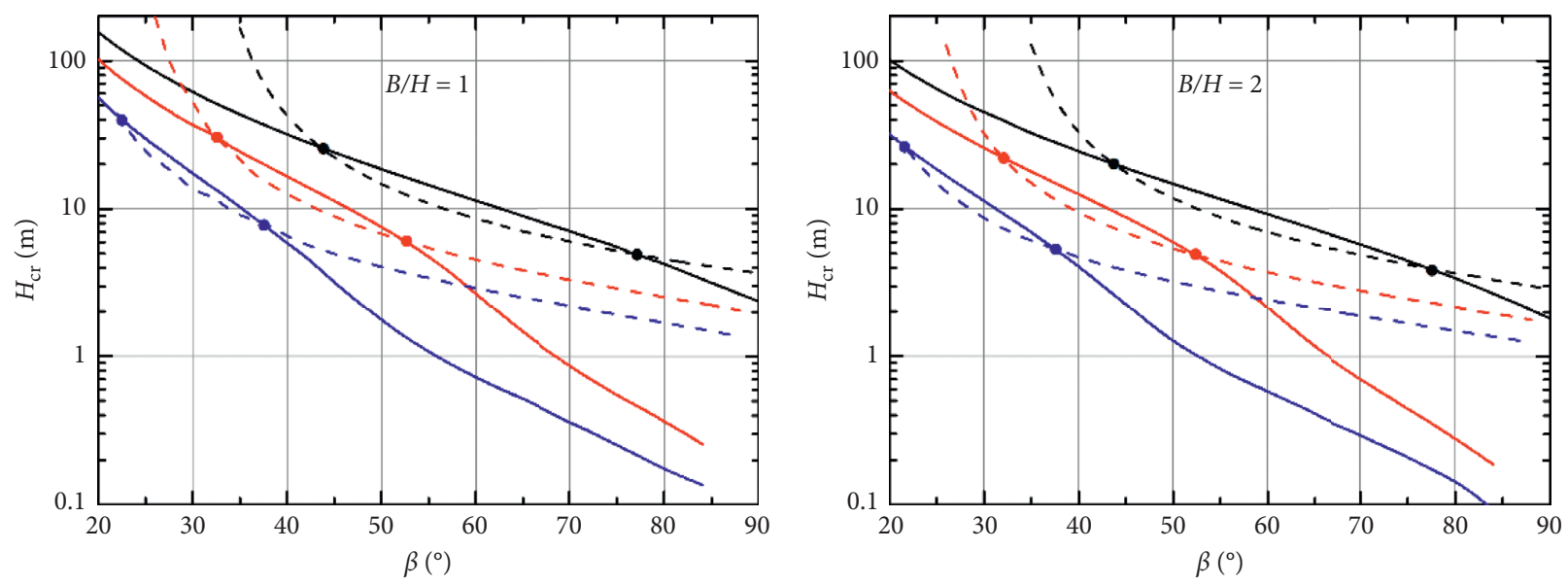

- Nonlinear results $\left(r_{\mathrm{u}}=0\right)$

- - - Linear results $\left(r_{\mathrm{u}}=0\right)$

- Nonlinear results $\left(r_{\mathrm{u}}=0.25\right)$

- - - Linear results $\left(r_{\mathrm{u}}=0.25\right)$

- Nonlinear results $\left(r_{\mathrm{u}}=0.5\right)$

- - - Linear results $\left(r_{\mathrm{u}}=0.5\right)$

(a)

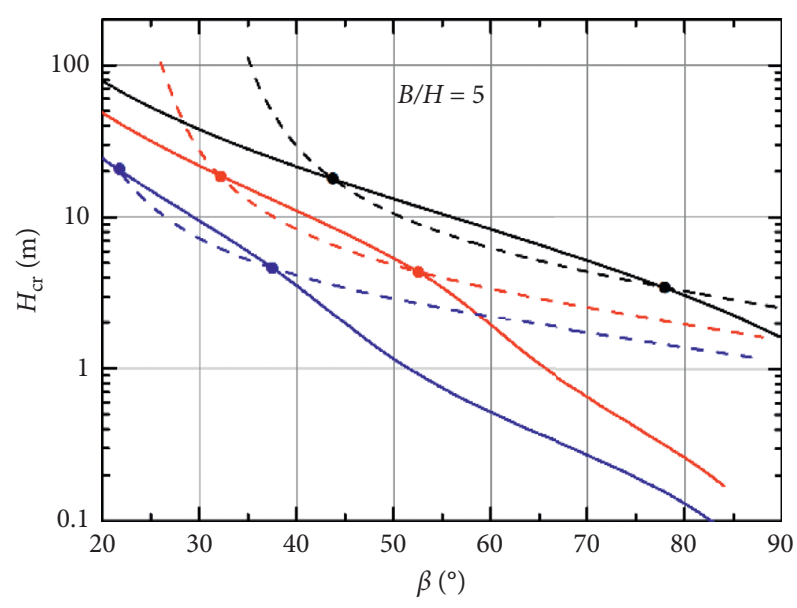

\footnotetext{
- Nonlinear results $\left(r_{\mathrm{u}}=0\right)$

- - - Linear results $\left(r_{\mathrm{u}}=0\right)$

- Nonlinear results $\left(r_{\mathrm{u}}=0.25\right)$

- - - Linear results $\left(r_{\mathrm{u}}=0.25\right)$

- Nonlinear results $\left(r_{\mathrm{u}}=0.5\right)$

- - - Linear results $\left(r_{\mathrm{u}}=0.5\right)$
}

(b)

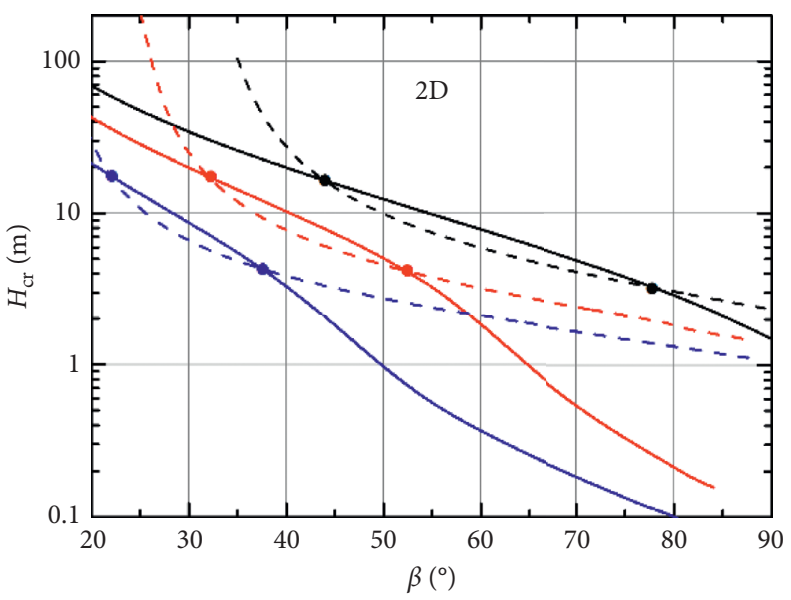

_ Nonlinear results $\left(r_{\mathrm{u}}=0\right)$

- - - Linear results $\left(r_{\mathrm{u}}=0\right)$

- Nonlinear results $\left(r_{\mathrm{u}}=0.25\right)$

- - L Linear results $\left(r_{\mathrm{u}}=0.25\right)$

- Nonlinear results $\left(r_{\mathrm{u}}=0.5\right)$

- - - Linear results $\left(r_{\mathrm{u}}=0.5\right)$

(c)

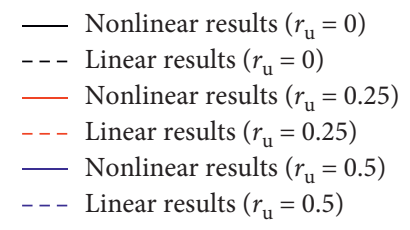

(d)

Figure 8: Critical heights of London clay slopes undergoing different pore-water pressures. (a) $B / H=1$. (b) $B / H=2$. (c) B/H=5. (d) $2 \mathrm{D}$.

Here, the definitions of these notations $\theta_{0}, \theta_{h}, r_{0}$, and $r_{0}{ }^{\prime}$ have been illustrated Section 2.3.

From equation (13), the optimized critical height $H_{\mathrm{cr}}$ is the minimum value of two least upper bounds derived from the two formulas for face-failure and base-failure mechanisms. Based on the computer codes of MATLAB software, the least upper-bound solutions were derived from an optimization procedure of Chen [40]. Once the least upper bound on the critical height of a given slope is derived in the optimization procedure, the variables $\theta_{0}, \theta_{\mathrm{h}}, r_{0}{ }^{\prime} / r_{0}, b / H, n$ or $\beta^{\prime}$, and $\phi_{e}$ will be simultaneously obtained as certain values.
Meanwhile, the corresponding critical slip surface (the intersection of failure mechanism and slope body) can also be obtained by determinate variables $\theta_{0}, \theta_{h}, r_{0}{ }^{\prime} / r_{0}, b / H, n$ or $\beta^{\prime}$, and $\phi_{e}$. Note that the variable $\phi_{e}$ is not only the apex angle of $3 \mathrm{D}$ failure mechanism but also the equivalent friction angle determining the tangent line location on nonlinear PL envelope. More detailed relationships between the variable $\phi_{e}$ and other parameters can be found in the functions of work rates in this study and [3]. Since the tangent line will lead to equivalent or higher shear strengths than the nonlinear PL envelop in the same scope of normal stresses, the solutions 

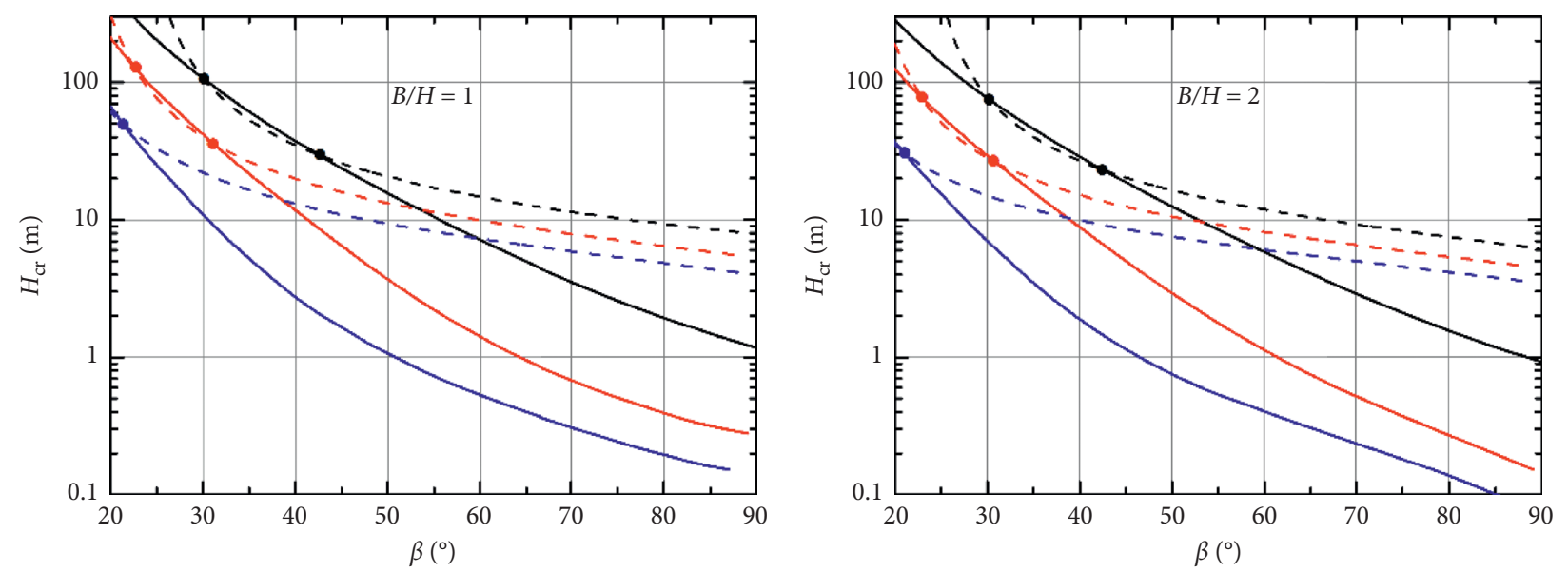

- Nonlinear results $\left(r_{\mathrm{u}}=0\right)$

- - Linear results $\left(r_{\mathrm{u}}=0\right)$

- Nonlinear results $\left(r_{\mathrm{u}}=0.25\right)$

- - - Linear results $\left(r_{\mathrm{u}}=0.25\right)$

- Nonlinear results $\left(r_{\mathrm{u}}=0.5\right)$

- - - Linear results $\left(r_{\mathrm{u}}=0.5\right)$

(a)

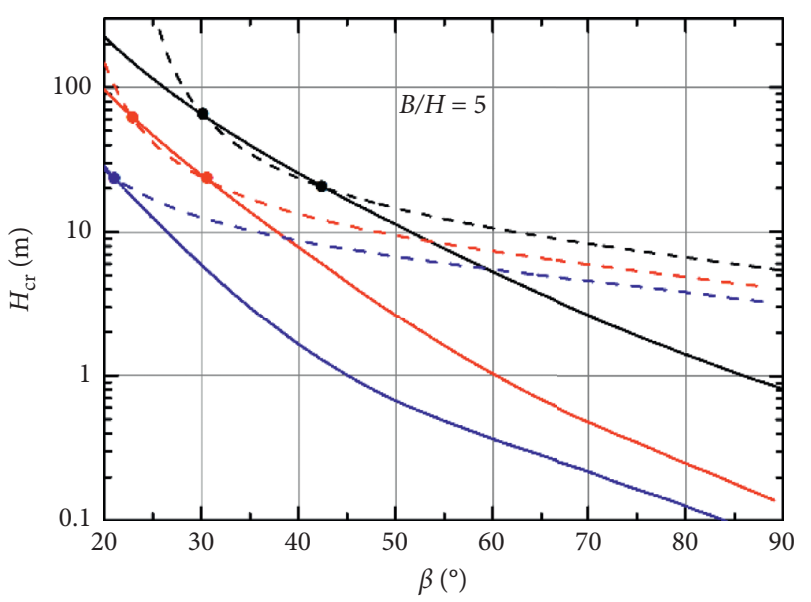

- Nonlinear results $\left(r_{\mathrm{u}}=0\right)$

- - Linear results $\left(r_{\mathrm{u}}=0\right)$

- Nonlinear results $\left(r_{\mathrm{u}}=0.25\right)$

- - - Linear results $\left(r_{\mathrm{u}}=0.25\right)$

- Nonlinear results $\left(r_{\mathrm{u}}=0.5\right)$

- - - Linear results $\left(r_{\mathrm{u}}=0.5\right)$

(b)

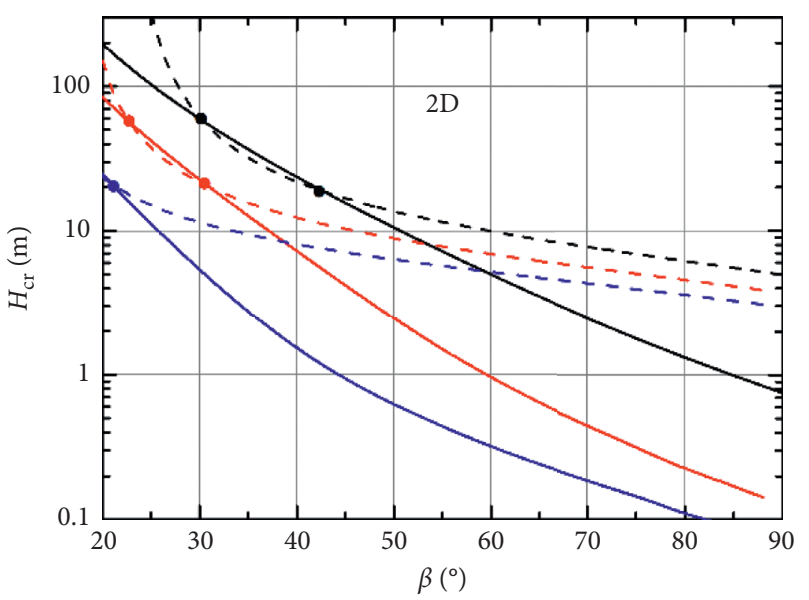

- Nonlinear results $\left(r_{\mathrm{u}}=0\right)$

- - - Linear results $\left(r_{\mathrm{u}}=0\right)$

- Nonlinear results $\left(r_{\mathrm{u}}=0.25\right)$

- - - Linear results $\left(r_{\mathrm{u}}=0.25\right)$

- Nonlinear results $\left(r_{\mathrm{u}}=0.5\right)$

- - - Linear results $\left(r_{\mathrm{u}}=0.5\right)$

(c)

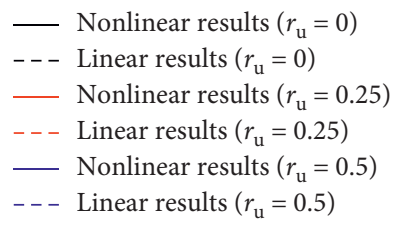

(d)

FiguRE 9: Critical heights of Upper Lias clay slopes undergoing different pore-water pressures. (a) $B / H=1$. (b) $B / H=2$. (c) B/H=5. (d) 2D.

derived by the tangential method can be upper bounds of critical loads.

\section{Slope Examples}

To illustrate the effects of pore-water pressures on slope assessment associated with linear MC and nonlinear PL strength envelopes, this study adopted the same four clay slope examples as presented by Gao et al. [24]. The four types of clays are Israeli clay, London clay, Upper Lias clay, and Oxford clay. The experiment data and the corresponding linear and nonlinear criteria for four clays have been presented in Figure 6. The unit weight, linear, and nonlinear strength parameters of four clays is shown in Table 1.

\section{Results and Discussion}

4.1. Effects of Pore-Water Pressures on Slope Critical Heights. For the above four slopes, the influences of pore-water pressures on slope critical heights derived by linear and nonlinear envelopes have been studied in this section. Figures 7-10 presented the critical heights of four slopes 


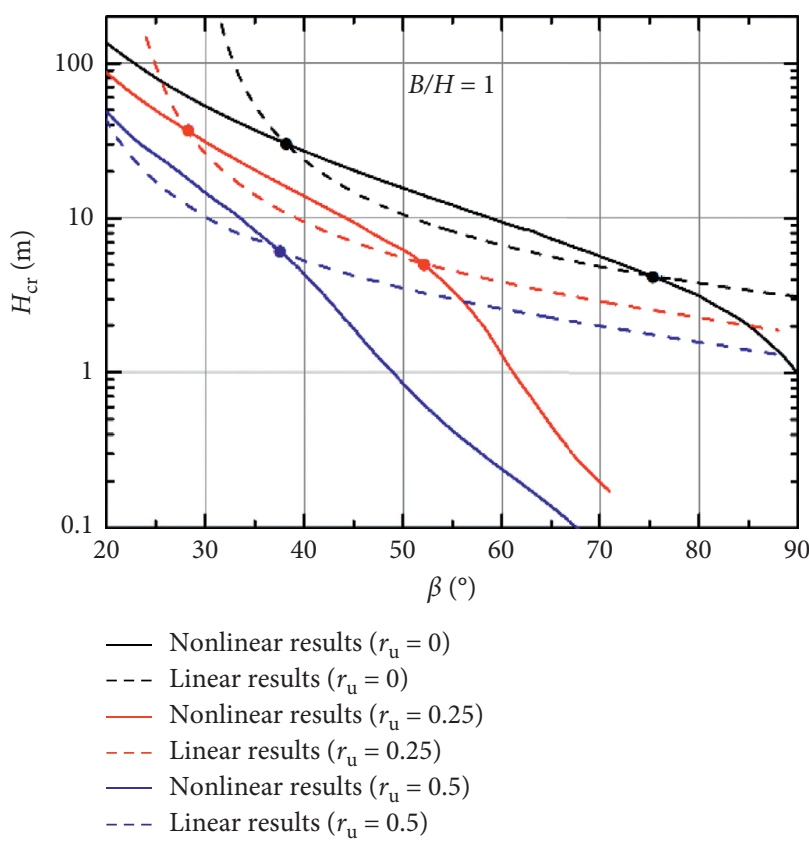

(a)

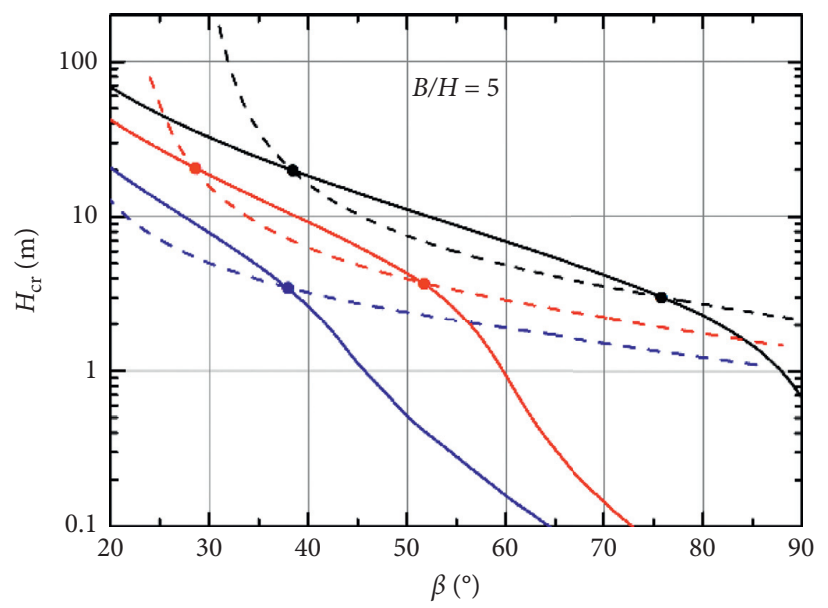

\footnotetext{
- Nonlinear results $\left(r_{\mathrm{u}}=0\right)$

- - - Linear results $\left(r_{\mathrm{u}}=0\right)$

- Nonlinear results $\left(r_{\mathrm{u}}=0.25\right)$

- - - Linear results $\left(r_{\mathrm{u}}=0.25\right)$

- Nonlinear results $\left(r_{\mathrm{u}}=0.5\right)$

- - - Linear results $\left(r_{\mathrm{u}}=0.5\right)$
}

(c)

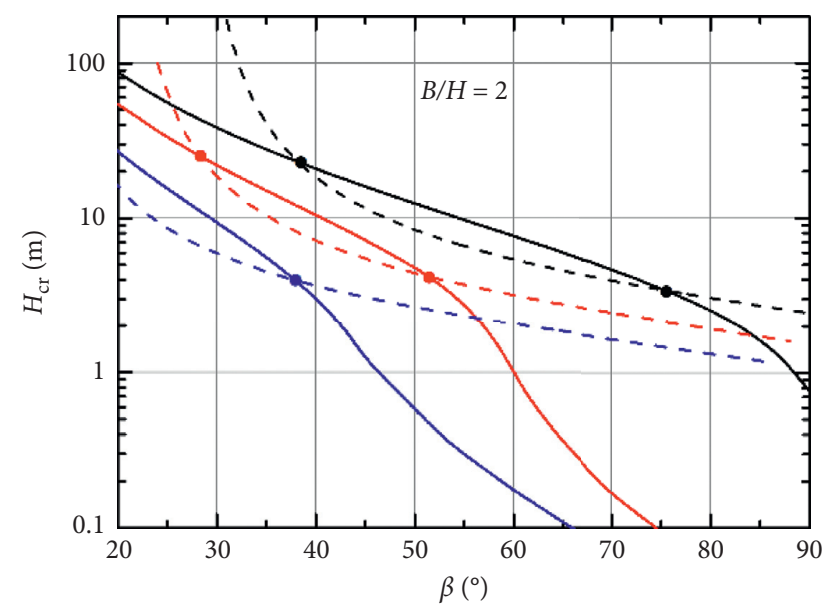

- Nonlinear results $\left(r_{\mathrm{u}}=0\right)$

- - Linear results $\left(r_{\mathrm{u}}=0\right)$

- Nonlinear results $\left(r_{\mathrm{u}}=0.25\right)$

- - Linear results $\left(r_{\mathrm{u}}=0.25\right)$

- Nonlinear results $\left(r_{\mathrm{u}}=0.5\right)$

- - Linear results $\left(r_{\mathrm{u}}=0.5\right)$

(b)

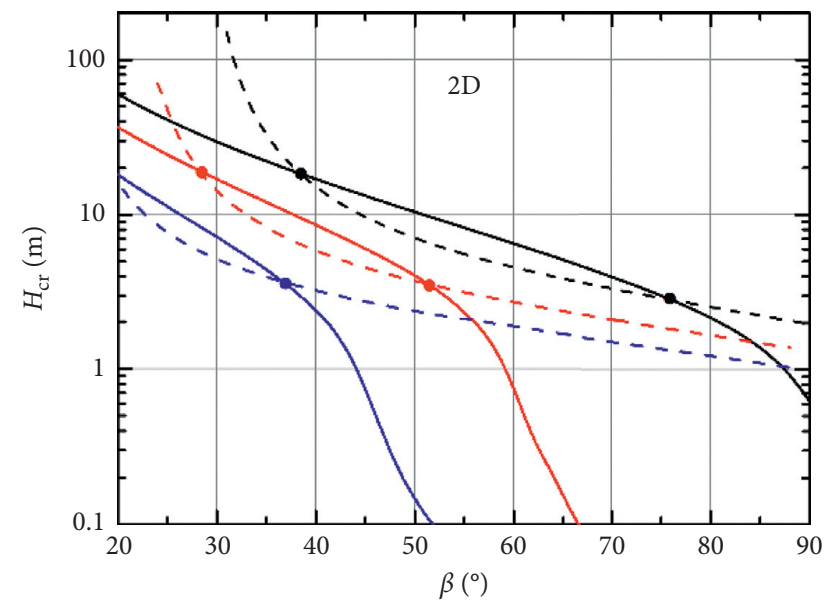

- Nonlinear results $\left(r_{\mathrm{u}}=0\right)$

- - - Linear results $\left(r_{\mathrm{u}}=0\right)$

- Nonlinear results $\left(r_{\mathrm{u}}=0.25\right)$

- - - Linear results $\left(r_{\mathrm{u}}=0.25\right)$

- Nonlinear results $\left(r_{\mathrm{u}}=0.5\right)$

- - - Linear results $\left(r_{\mathrm{u}}=0.5\right)$

(d)

Figure 10: Critical heights of Oxford clay slopes undergoing different pore-water pressures. (a) $B / H=1$. (b) $B / H=2$. $(c) B / H=5$. (d) $2 \mathrm{D}$.

with respect to different $3 \mathrm{D}$ effects and pore-water pressures. In these figures, the solid lines related to the critical heights are derived by nonlinear PL criterion (nonlinear results for short), and the dotted lines related to the critical heights are derived by linear MC criterion (linear results for short). Lines in different colors represented the solutions with different pore-water pressure coefficients $r_{\mathrm{u}}(0.0,0.25$, and 0.5).

It can be found from Figures 7-10 that two critical slope inclinations $\beta_{1}$ and $\beta_{2}$ associated with linear and nonlinear results will change as pore-water pressure coefficient $r_{\mathrm{u}}$ changes for any slope example. When pore-water pressure coefficient $r_{\mathrm{u}}$ increases, the critical inclination $\beta_{1}$ becomes smaller, and $\beta_{2}$ also gradually decreases or even disappears. The positions of two critical inclinations $\beta_{1}$ and $\beta_{2}$ will gradually approach as the pore-water pressure coefficient $r_{\mathrm{u}}$ increases. Besides, by comparing the linear and nonlinear results with different values of $r_{\mathrm{u}}$, the differences between linear and nonlinear results for slopes with $\beta>\beta_{2}$ were found to become significant as $r_{\mathrm{u}}$ increases. The above 


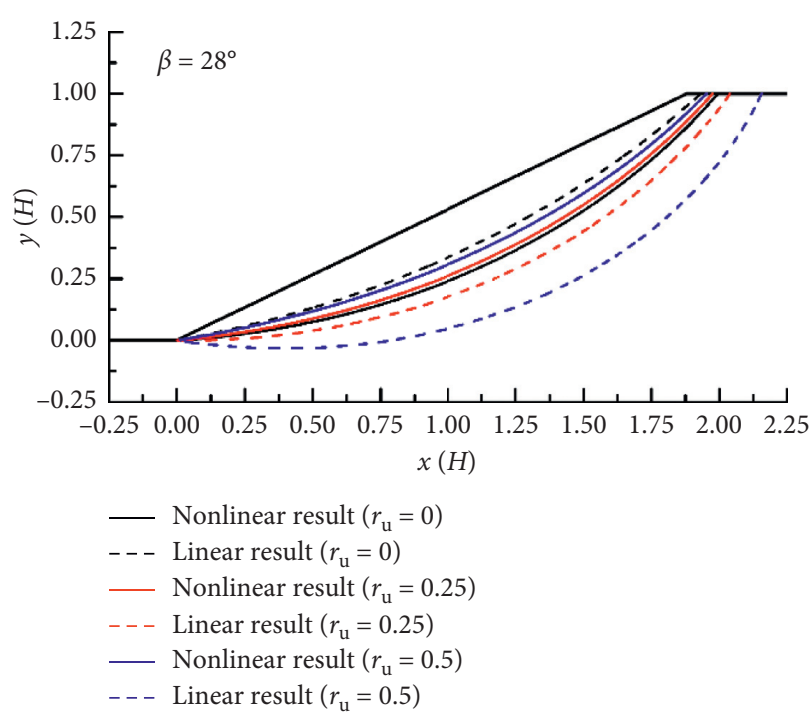

(a)

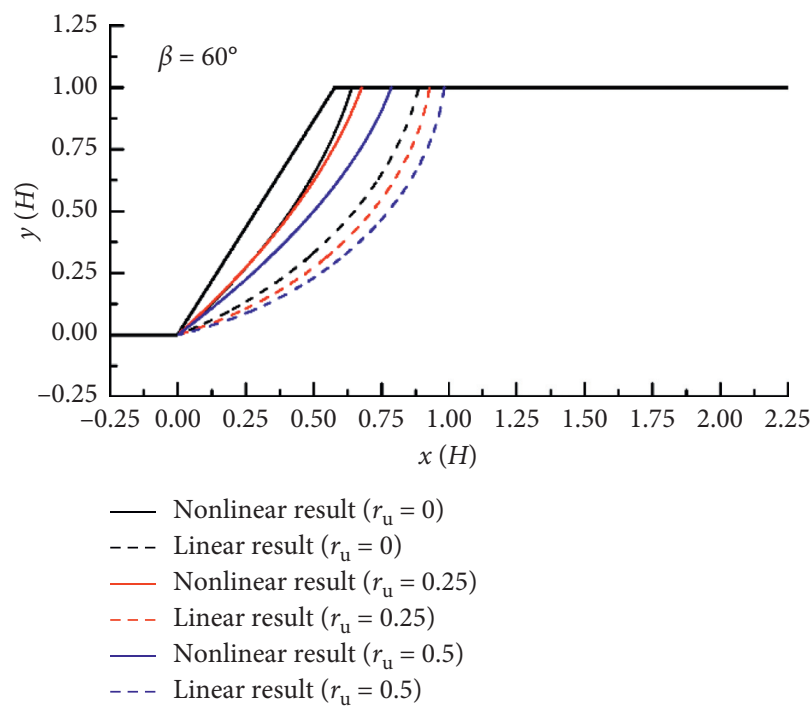

(c)

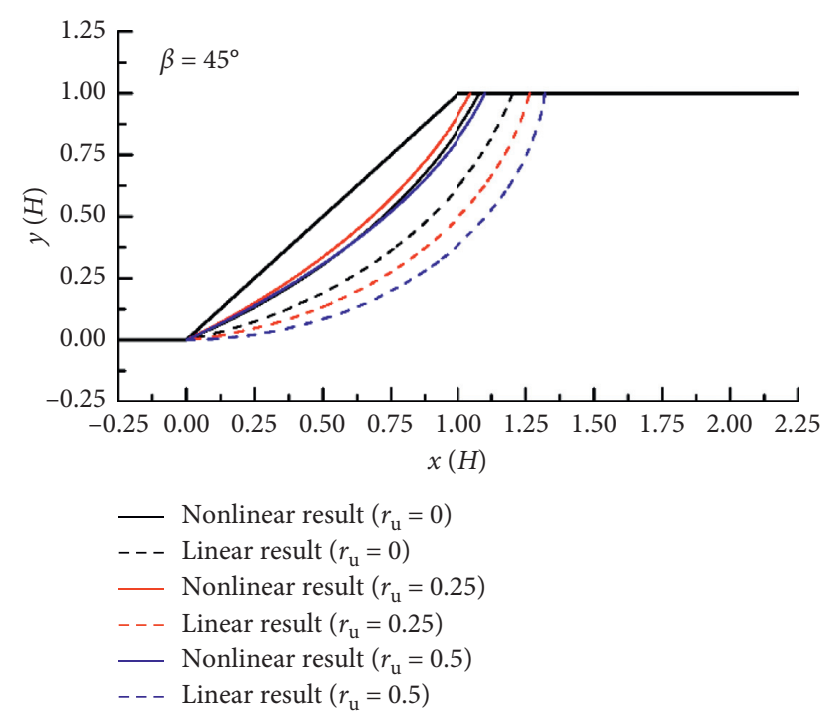

(b)

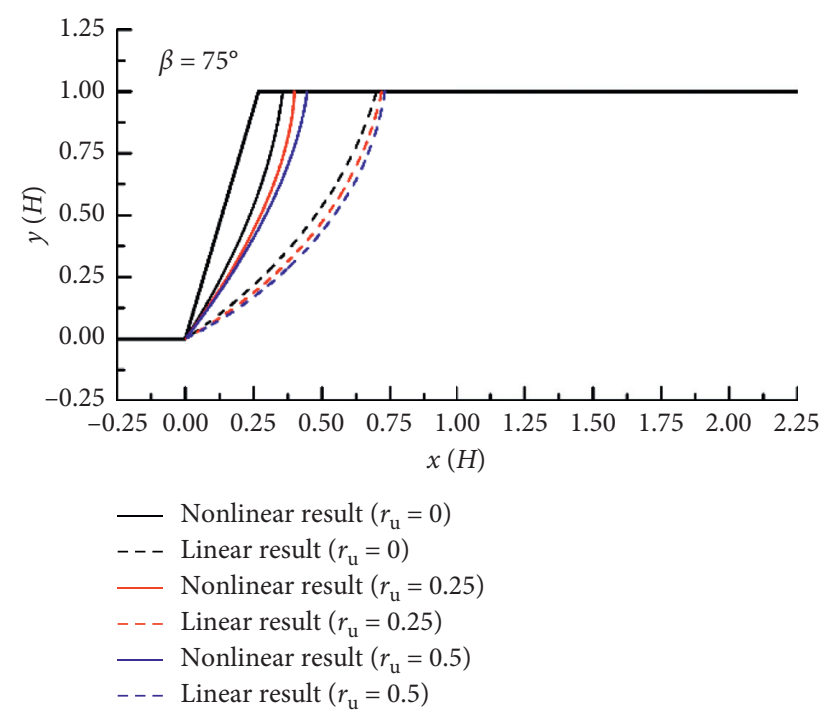

(d)

FIGURE 11: Critical slip surfaces of Israeli clay slopes undergoing different pore-water pressures. (a) $\beta=28^{\circ}$. (b) $\beta=45^{\circ}$. (c) $\beta=60^{\circ}$. (d) $\beta=75^{\circ}$.

phenomenon may illustrate that the linear MC criterion will result in more obviously higher critical height than the nonlinear PL criterion for steeper slopes undergoing porewater pressures. In this situation, the importance of the application of the nonlinear criteria in slope stability evaluations tends to be outstanding. However, the differences between linear and nonlinear results for slopes $\left(\beta_{1}<\beta<\beta_{2}\right)$ seem to become smaller with $r_{\mathrm{u}}$ increasing. The underestimation of slope safety derived by linear MC envelope will be less obvious for these slopes subjected to pore-water pressures.

Simultaneously, 3D effects on the distinctions between linear and nonlinear results under different pore-pressure coefficients $r_{\mathrm{u}}$ are illustrated in Figures 7-10. As shown in graphs (a)-(d) in each figure, the locations of two critical slope inclinations $\left(\beta_{1}\right.$ and $\left.\beta_{2}\right)$ will change slightly as the relative width $B / H$ increases from 1 to $\infty$ (2D). The differences between the linear and nonlinear results seem to be more significant as $B / H$ decreases for slopes undergoing pore-water pressures. This means that using linear $\mathrm{MC}$ criterion for slope stability analysis will more obviously overestimate or underestimate the stability of $3 \mathrm{D}$ slopes undergoing pore-water pressures.

4.2. Effects of Pore-Water Pressures on Slope Slip Surfaces. Figures 11 and 12 show the critical slip surfaces for 2D slopes in Israeli clay and London clay subjected to different porewater pressures. These figures can help address the influences of pore-water pressures on slope critical slip surfaces associated with linear and nonlinear envelopes. Similarly, the solid lines and the dotted lines represented the critical slip surfaces derived by nonlinear PL criterion and linear MC criterion, respectively. Slope critical slip surfaces under 


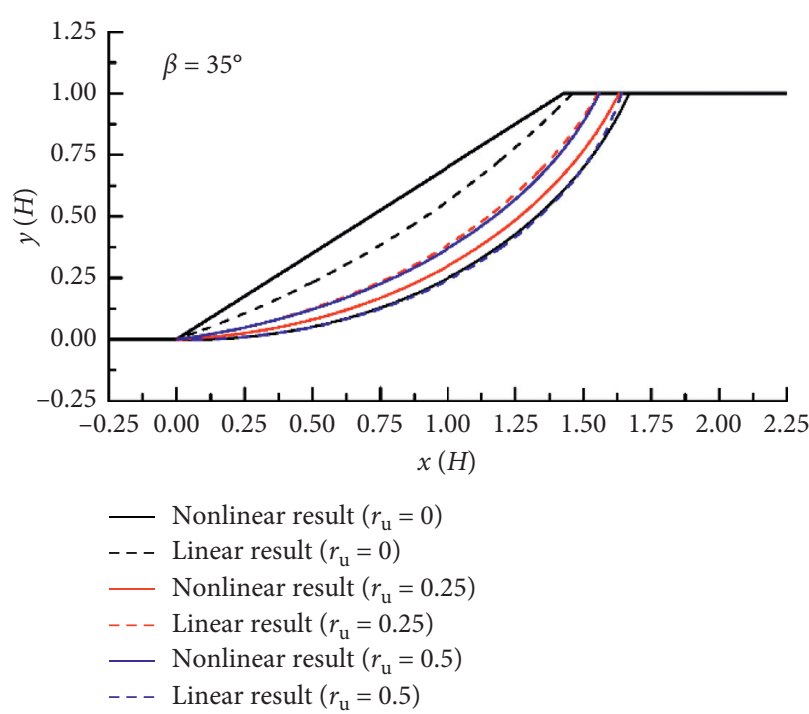

(a)

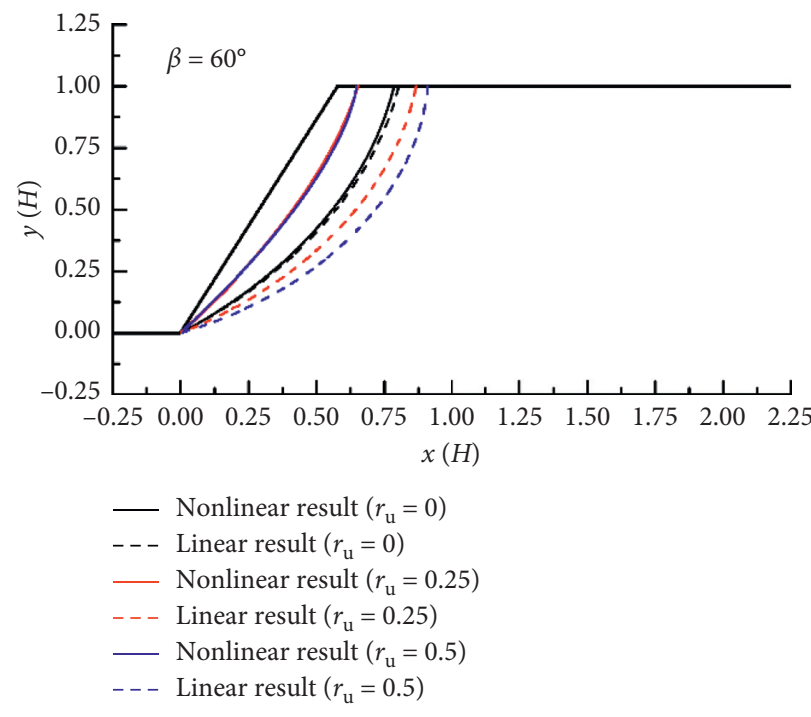

(c)

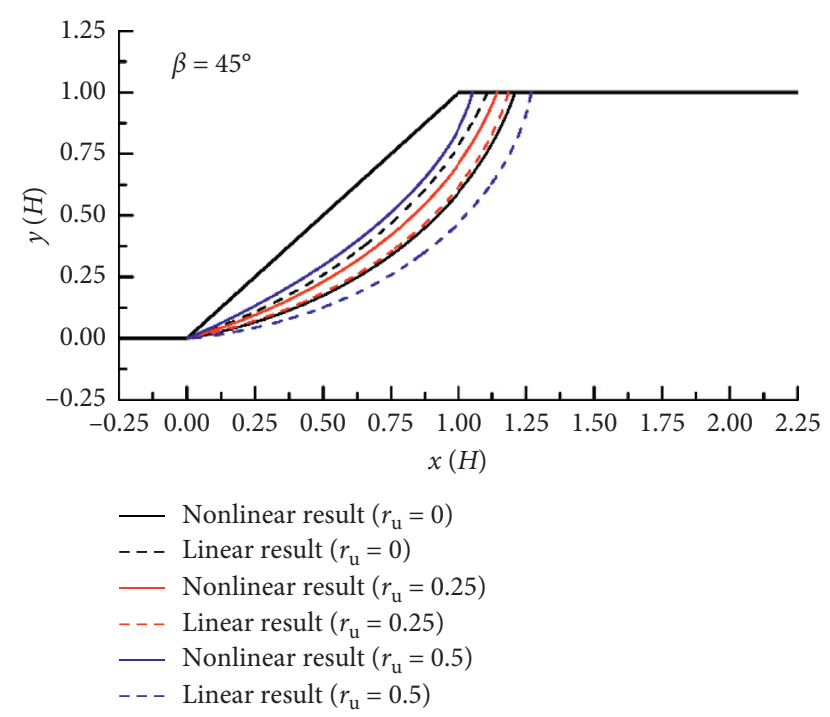

(b)

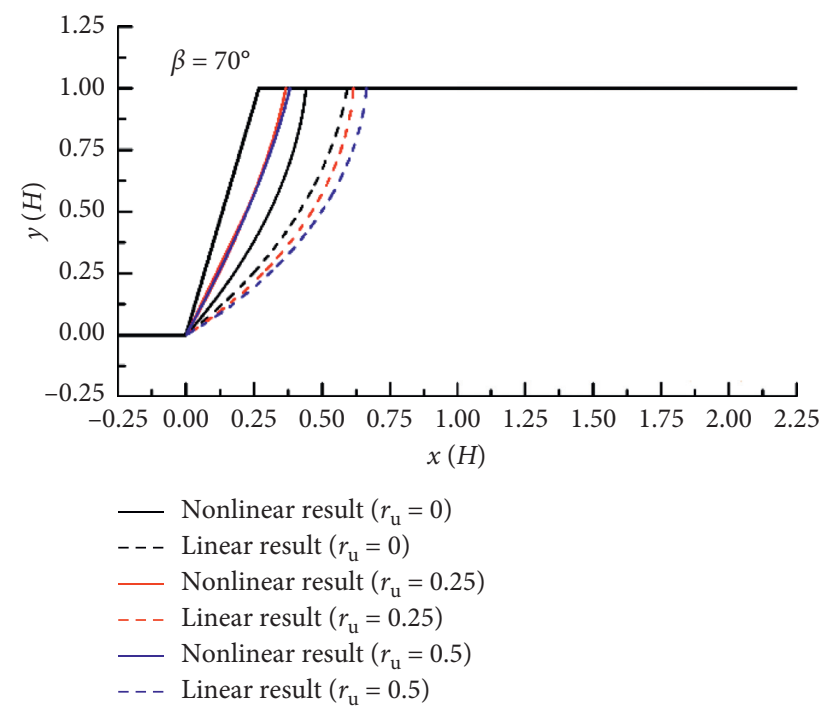

(d)

Figure 12: Critical slip surfaces of London clay slopes undergoing different pore-water pressures. (a) $\beta=35^{\circ}$. (b) $\beta=45^{\circ}$. (c) $\beta=60^{\circ}$. (d) $\beta=75^{\circ}$.

different pore-water pressures were also presented by different color lines. It should be noted that four slope inclinations in ranges of $\beta<\beta_{1}, \beta_{1}<\beta<\beta_{2}$, and $\beta>\beta_{2}$ for two slopes were considered in this section. The final type of failure mechanisms for these slope examples was obtained to be the toe-failure mechanism.

As presented in Figures 11 and 12, the critical slip surfaces derived by two strength criteria were found to have different relative locations for slopes with various inclinations. For gentle slopes $\left(\beta<\beta_{1}\right)$ with high normal stresses on slip surfaces, the average shear strengths of the linear envelope are smaller than those of the nonlinear envelope (Figure 6). Hence, the critical slip surfaces with linear envelope are shallower than those with nonlinear envelope. When the slope inclination satisfies $\beta>\beta_{2}$, the average shear strengths of the linear envelope are higher than those of the nonlinear envelope, and the linear criterion will result in a deeper slip surface than the nonlinear criterion. Baker [17] made similar findings in the limit equilibrium method for stability evaluation of slope examples with another nonlinear envelope.

From Figures 11 and 12, the influences of pore-water pressures on slope critical slip surfaces associated with linear and nonlinear envelopes were found to be quite different. As expected, the critical slip surfaces for slopes using the linear $\mathrm{MC}$ criterion will become deeper with increase in pore-water pressure coefficient $r_{\mathrm{u}}$. However, the critical slip surfaces of gentle slopes $\left(\beta<45^{\circ}\right)$ with nonlinear PL criterion will become shallower as $r_{\mathrm{u}}$ increases, but the change law for the critical slip surfaces of steep slopes $\left(\beta \geq 45^{\circ}\right)$ seemed to be hardly consistent. Besides, the effects of pore-water pressures on critical slip surfaces associated with two failure criteria tend to be less obvious for slopes with bigger inclinations. 


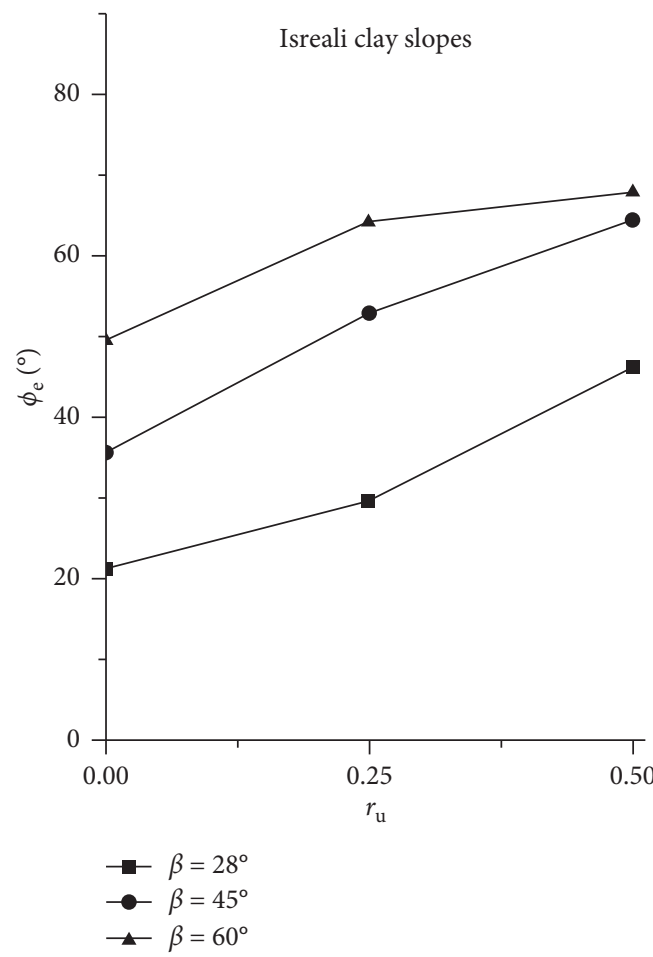

(a)

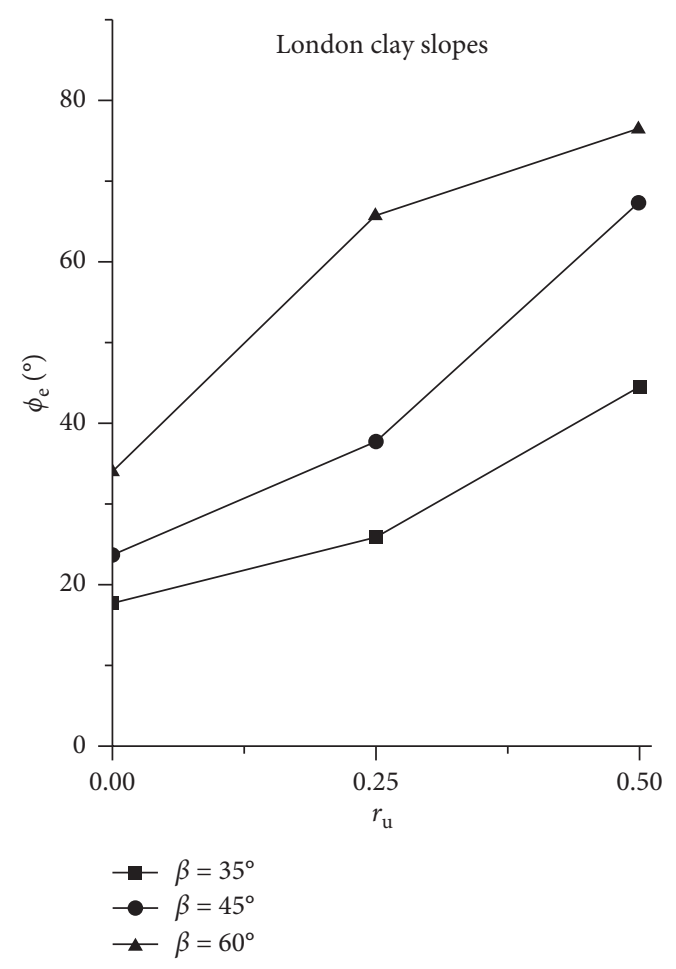

(b)

FIgURE 13: Effect of $r_{u}$ on equivalent friction angle $\phi_{\mathrm{e}}$. (a) Israeli clay slope. (b) London clay slope.

The emergence of the above phenomenon may relate to the influence of equivalent internal friction angle $\phi_{\mathrm{e}}$ on the slope critical slip surface. By using the MC criterion, the slopes have deeper critical slip surfaces as pore-water pressure coefficient $r_{\mathrm{u}}$ becomes bigger or as internal friction angle $\phi$ gets smaller. In stability analyses of slopes with nonlinear PL criterion, the equivalent internal friction angle $\phi_{\mathrm{e}}$ is not constant. As presented in Figure 13, equivalent internal friction angle $\phi_{\mathrm{e}}$ becomes bigger as $r_{\mathrm{u}}$ increases, but the increasing trend will be gradually flat for steep slopes. It may mean that the equivalent internal friction angle $\phi_{\mathrm{e}}$ has a more significant influence than the pore-water pressure on critical slip surfaces of gentle slopes $\left(\beta<45^{\circ}\right)$. Then, the gentle slope slip surfaces associated with the PL criterion appear to be shallower with the increasing pore-water pressure coefficient $r_{\mathrm{u}}$. While, for steep slopes $\left(\beta \geq 45^{\circ}\right)$, the effects of $\phi_{\mathrm{e}}$ and $r_{\mathrm{u}}$ on the slope critical slip surface seemed to be mutually restricted. Hence, the critical slip surfaces of steep slopes tend to have no consistent changing law as $r_{\mathrm{u}}$ increases.

\section{Conclusions}

Based on extended 3D rotational mechanisms for slope stability assessment with linear MC envelope, this paper used the tangential method to combine a nonlinear PL criterion into upper-bound limit analysis method. The porewater pressure coefficient was utilized to assess the effect of pore-water pressure on the slope stability. For typical slope examples, the slope critical heights and corresponding slip surfaces associated with linear and nonlinear strength envelopes were derived with respect to different pore-water pressures and slope geometries. The linear and nonlinear results were compared to illustrate significant influences of pore-water pressures on the stability of slopes in $2 \mathrm{D}$ and $3 \mathrm{D}$ conditions. The main conclusions from presented results and discussions are drawn as follows:

(1) As pore-water pressure coefficient $r_{\mathrm{u}}$ increases, the positions of two critical inclinations $\beta_{1}$ and $\beta_{2}$ between the linear and nonlinear results gradually approach with $\beta_{1}$ becoming smaller and $\beta_{2}$ decreasing or even disappearing. For steeper slopes undergoing pore-water pressures, using the linear criterion will more obviously overestimate the critical height. The application of nonlinear criteria in slope stability analysis tends to become more significant.

(2) For slopes undergoing pore-water pressures, the differences between linear and nonlinear results for slope critical heights become more obvious with the relative width $B / H$ decreasing. The linear $\mathrm{MC}$ criterion will result in more pronounced overestimation or underestimation of the safety of actual slopes with smaller widths.

(3) The influences of pore-water pressures on slope critical slip surfaces associated with nonlinear criterion are quite different from those associated with linear criterion. For slopes with the nonlinear criterion, the critical slip surfaces of gentle slopes $\left(\beta<45^{\circ}\right)$ become shallower as $r_{\mathrm{u}}$ increases. However, the change law for the critical slip surfaces of steep 
slopes $\left(\beta \geq 45^{\circ}\right)$ seems to be hardly consistent with $r_{\mathrm{u}}$ increasing. This is due to the fact that the increase of equivalent internal friction angle caused by the increasing pore-water pressure tends to weaken for steep slopes.

\section{Data Availability}

The data used to support the findings of this study are included within the article.

\section{Conflicts of Interest}

The authors declare that there are no conflicts of interest regarding the publication of this paper.

\section{Acknowledgments}

This work was sponsored by National Natural Science Foundation of China (Grant nos. 51708310 and 51809160) and Shandong Provincial Natural Science Foundation, China (Grant nos. ZR2017BEE066 and ZR2017BEE035).

\section{References}

[1] W. F. Chen, Limit Analysis and Soil Plasticity, Elsevier, Amsterdam, Netherlands, 1975.

[2] R. L. Michalowski and A. Drescher, "Three-dimensional stability of slopes and excavations," Géotechnique, vol. 59, no. 10 , pp. 839-850, 2009.

[3] Y. F. Gao, F. Zhang, G. H. Lei, and D. Y. Li, “An extended limit analysis of three-dimensional slope stability," Géotechnique, vol. 63, no. 6, pp. 518-524, 2013.

[4] P. Rao, J. Wu, Z. Mo et al., "3D Limit analysis of the transient stability of slope during pile driving in nonhomogeneous and anisotropic soil," Advances in Civil Engineering, vol. 2020, pp. 1-10, Article ID 7560219, 2020.

[5] S. Yang, B. Leshchinsky, K. Cui et al., "Influence of failure mechanism on seismic bearing capacity factors for shallow foundations near slopes," Géotechnique, pp. 1-46, 2020.

[6] X. Ye, S. Wang, Q. Li et al., "Negative effect of installation on performance of a compaction-grouted soil nail in poorly graded Stockton beach sand," Journal of Geotechnical and Geoenvironmental Engineering, vol. 146, no. 8, Article ID 04020061, 2020.

[7] X. Ye, S. Wang, S. Zhang et al., "The compaction effect on the performance of a compaction-grouted soil nail in sand," Acta Geotechnica, vol. 15, pp. 2983-2995, 2020.

[8] A. W. Bishop, D. L. Webb, and P. I. Lewin, "Undisturbed samples of London clay from the Ashford common shaft: strength-effective stress relationships," Géotechnique, vol. 15, no. 1, pp. 1-31, 1965.

[9] A. Marsland, "The shear strength of stiff fissured clays," in Proceedings of the Roscoe Memorial Symposium on StressStrain Behaviour of Soils, pp. 59-68, Cambridge University, Cambridge, UK, 1971.

[10] G. Lefebvre, "Strength and slope stability in Canadian soft clay deposits," Canadian Geotechnical Journal, vol. 3, no. 2, pp. 420-442, 1981.

[11] M. Maksimovic, "Nonlinear failure envelope for soils," Journal of Geotechnical Engineering, vol. 115, no. 4, pp. 581$586,1989$.
[12] R. Baker, "Nonlinear Mohr envelopes based on triaxial data," Journal of Geotechnical and Geoenvironmental Engineering, vol. 130, no. 5, pp. 498-506, 2004.

[13] Q. Lin, P. Cao, P. Wang et al., "Study of post-peak strain softening mechanical behaviour of rock material based on Hoek-Brown criterion," Advances in Civil Engineering, vol. 2018, pp. 1-9, Article ID 6190376, 2018.

[14] J. A. Charles and M. M. Soares, "The stability of slopes in soils with nonlinear failure envelopes," Canadian Geotechnical Journal, vol. 21, no. 3, pp. 397-406, 1984.

[15] M. Srbulov, "On the influence of soil strength brittleness and nonlinearity on slope stability," Computers and Geotechnics, vol. 20, no. 1, pp. 95-104, 1997.

[16] J.-C. Jiang, R. Baker, and T. Yamagami, "The effect of strength envelope nonlinearity on slope stability computations," $\mathrm{Ca}$ nadian Geotechnical Journal, vol. 40, no. 2, pp. 308-325, 2003.

[17] R. Baker, "Inter-relations between experimental and computational aspects of slope stability analysis," International Journal for Numerical and Analytical Methods in Geomechanics, vol. 27, no. 5, pp. 379-401, 2003.

[18] R. Baker, "Stability chart for zero tensile strength HoekBrown materials-the variational solution and its engineering implications," Soils and Foundations, vol. 44, no. 3, pp. 125-132, 2004.

[19] H. T. Eid, "Two- and three-dimensional analyses of translational slides in soils with nonlinear failure envelopes," Canadian Geotechnical Journal, vol. 47, no. 4, pp. 388-399, 2010.

[20] H. T. Eid, "Stability charts for uniform slopes in soils with nonlinear failure envelopes," Engineering Geology, vol. 168, pp. 38-45, 2014.

[21] D. Deng and L. Li, "Limit equilibrium analysis of slope stability with coupling nonlinear strength criterion and doublestrength reduction technique," International Journal of Geomechanics, vol. 19, no. 6, Article ID 04019052, 2019.

[22] A. Drescher and C. Christopoulos, "Limit analysis slope stability with nonlinear yield condition," International Journal for Numerical and Analytical Methods in Geomechanics, vol. 12, no. 3, pp. 341-345, 1988.

[23] X.-L. Yang and J.-H. Yin, "Slope stability analysis with nonlinear failure criterion," Journal of Engineering Mechanics, vol. 130, no. 3, pp. 267-273, 2004.

[24] Y. Gao, D. Wu, and F. Zhang, "Effects of nonlinear failure criterion on the three-dimensional stability analysis of uniform slopes," Engineering Geology, vol. 198, pp. 87-93, 2015.

[25] L.-h. Zhao, X. Cheng, H.-c. Dan, Z.-p. Tang, and Y. Zhang, "Effect of the vertical earthquake component on permanent seismic displacement of soil slopes based on the nonlinear Mohr-Coulomb failure criterion," Soils and Foundations, vol. 57, no. 2, pp. 237-251, 2017.

[26] Y. Li and X. Yang, "Seismic displacement of 3D slope reinforced by piles with nonlinear failure criterion," International Journal of Geomechanics, vol. 19, no. 6, Article ID 04019042, 2019.

[27] M. Popescu, K. Ugai, and A. Trandafir, "Linear versus nonlinear failure envelopes in LEM and FEM slope stability analysis," in Proceedings of the 8th International Symposium on Landslides, vol. 3, pp. 1227-1234, Cardiff, UK, June 2000.

[28] X. Li, "Finite element analysis of slope stability using a nonlinear failure criterion," Computers and Geotechnics, vol. 34, no. 3, pp. 127-136, 2007.

[29] D. Li and Y. Cheng, "Lower bound limit analysis using nonlinear failure criteria," Procedia Earth and Planetary Science, vol. 5, pp. 170-174, 2012. 
[30] Y. X. Li and X. L. Yang, "Soil-slope stability considering effect of soil-strength nonlinearity," International Journal of Geomechanics, vol. 19, no. 3, Article ID 04018201, 2019.

[31] R. L. Michalowski and S. S. Nadukuru, "Three-dimensional limit analysis of slopes with pore pressure," Journal of Geotechnical and Geoenvironmental Engineering, vol. 139, no. 9, pp. 1604-1610, 2013.

[32] Y. Gao, D. Zhu, F. Zhang, G. H. Lei, and H. Qin, "Stability analysis of three-dimensional slopes under water drawdown conditions," Canadian Geotechnical Journal, vol. 51, no. 11, pp. 1355-1364, 2014.

[33] Q. Pan, J. Xu, and D. Dias, "Three-dimensional stability of a slope subjected to seepage forces," International Journal of Geomechanics, vol. 17, no. 8, Article ID 04017035, 2017.

[34] Y. Zhu, Y. Xiao, and C. S. Vieira, "Slope stability from a hydrological perspective: taking typical soil slope as an example," Advances in Civil Engineering, vol. 2020, pp. 1-17, Article ID 1273603, 2020.

[35] X.-L. Yang and J.-F. Zou, "Stability factors for rock slopes subjected to pore water pressure based on the Hoek-Brown failure criterion," International Journal of Rock Mechanics and Mining Sciences, vol. 43, no. 7, pp. 1146-1152, 2006.

[36] Z. Saada, S. Maghous, and D. Garnier, "Stability analysis of rock slopes subjected to seepage forces using the modified Hoek-Brown criterion," International Journal of Rock Mechanics and Mining Sciences, vol. 55, pp. 45-54, 2012.

[37] J. Xu, Q. Pan, X. L. Yang et al., "Stability charts for rock slopes subjected to water drawdown based on the modified nonlinear Hoek-Brown failure criterion," International Journal of Geomechanics, vol. 18, no. 1, Article ID 04017133, 2018.

[38] X. J. Zhang and W. F. Chen, "Stability analysis of slopes with general nonlinear failure criterion," International Journal for Numerical and Analytical Methods in Geomechanics, vol. 11, no. 1, pp. 33-50, 1987.

[39] D. Wu, Y. Wang, Y. Qiu, J. Zhang, and Y. Wan, "Determination of Mohr-Coulomb parameters from nonlinear strength criteria for 3D slopes," Mathematical Problems in Engineering, vol. 2019, no. 4, pp. 1-12, 2019.

[40] Z.-Y. Chen, "Random trials used in determining global minimum factors of safety of slopes," Canadian Geotechnical Journal, vol. 29, no. 2, pp. 225-233, 1992. 